Journal of Sustainable Agricultural Sciences
http://jsas.journals.ekb.eg/

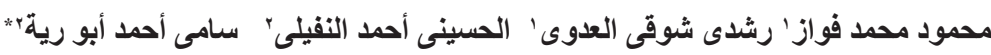

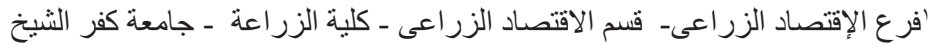

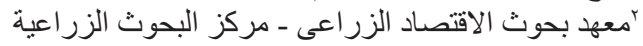

تنحصر مشكلة البحث في زيادة مساحة التعدى على الاراضى الزراعية حيث بلغت المساحة المتعدى عليها

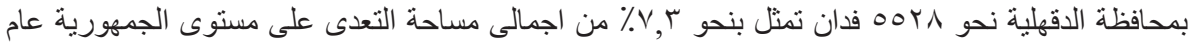

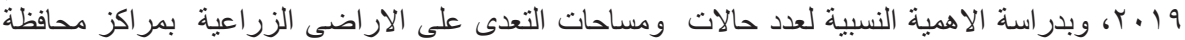

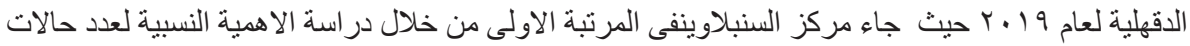

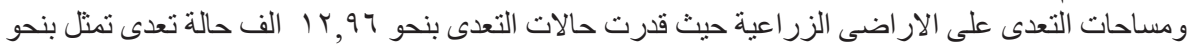

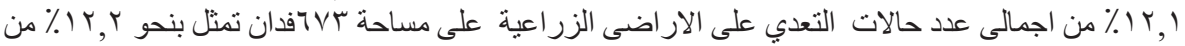

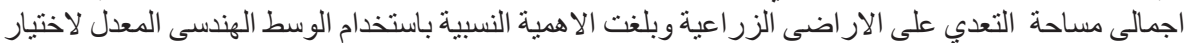

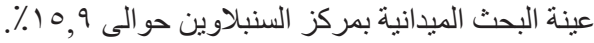

الكلمات الإفتتاحية: التعدى ، مخالفات البناء ، التجريف , الموارد الأرضية ، الأمن الغذائى ، الملكية العامة ،

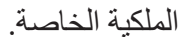

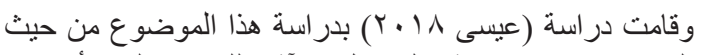

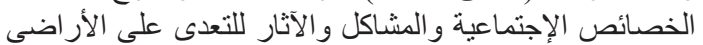

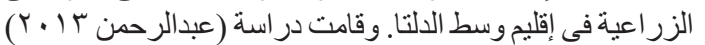

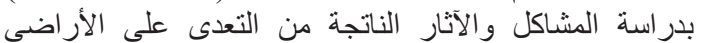

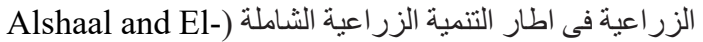

(Ramady, 2017

المشكلة البحثبة

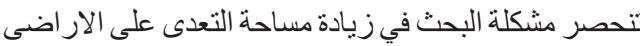

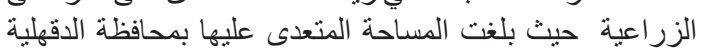

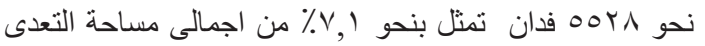

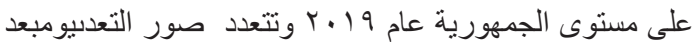

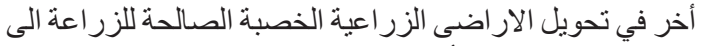

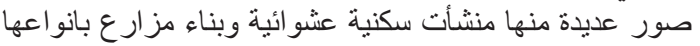

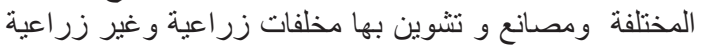

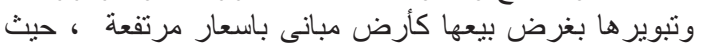

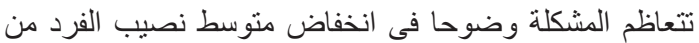

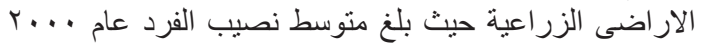

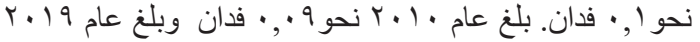

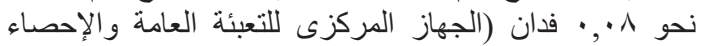

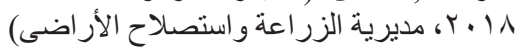

الأهداف البحثية

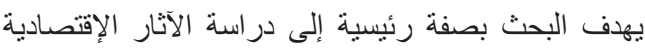

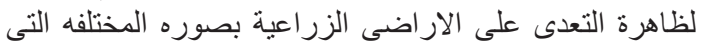

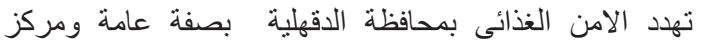

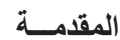

تعتبر ظاهرة التعدى على الاراضى الزراعية مشكلة اقتصادية

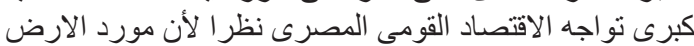

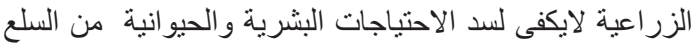

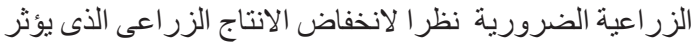

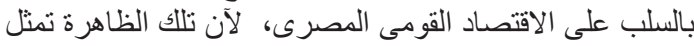

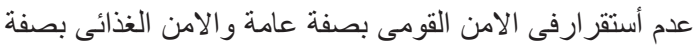

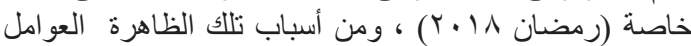

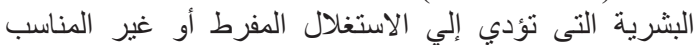

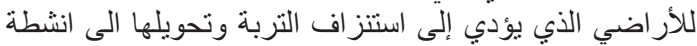

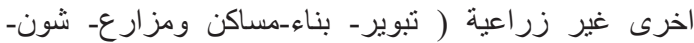

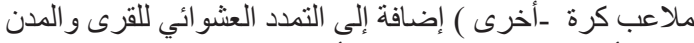

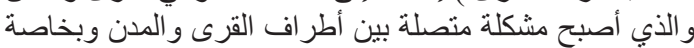

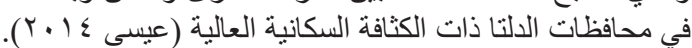

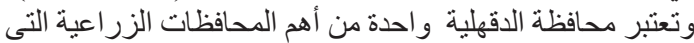

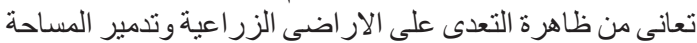

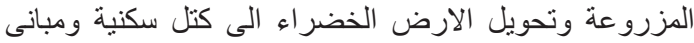

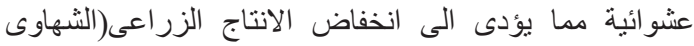

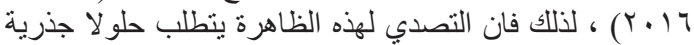

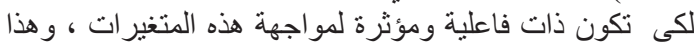
يتطلب فكر ا يحلل الإحداث الجارية ويتوقة التع الإحداث المستقبلية

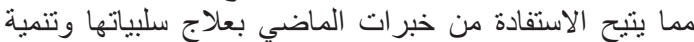

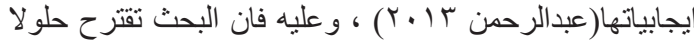

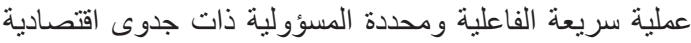

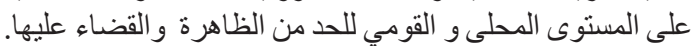

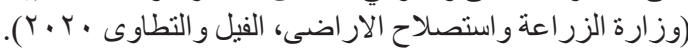

"Corresponding Author: Email: samyahmed5252@gmail.com DOI : $10.21608 /$ jsas.2020.27833.1215

Received: 13/4/2020;Accepted: 13/6/2020

C2019 National Information and Documentation Center (NIDOC) 


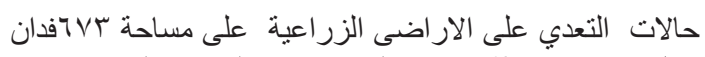

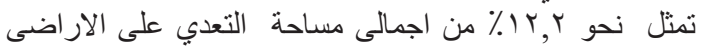

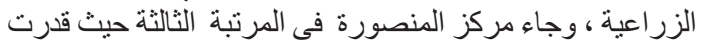

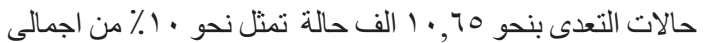

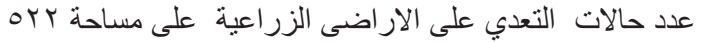

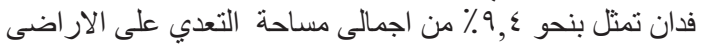

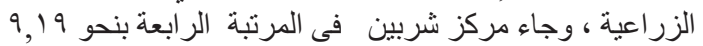

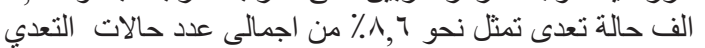

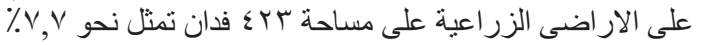

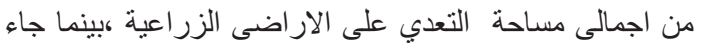

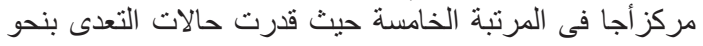

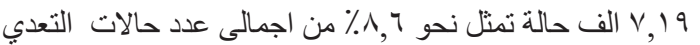

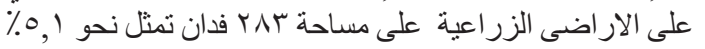

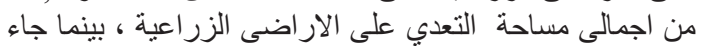

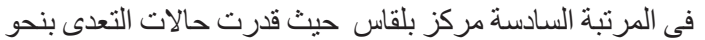

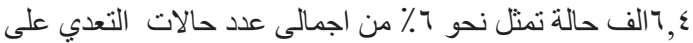

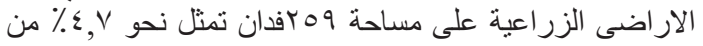

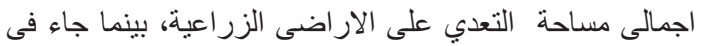

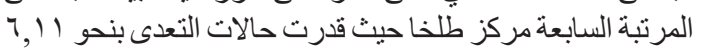

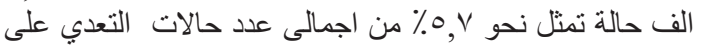

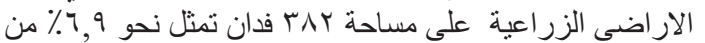

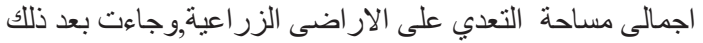

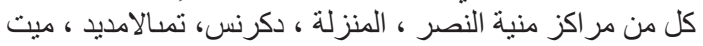

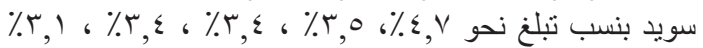

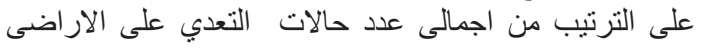

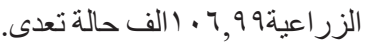

ثانيا :التوزيع الجغر افى لحالات الاز الة ومساحتها فى مر اكز

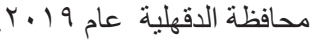

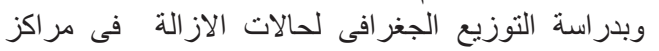

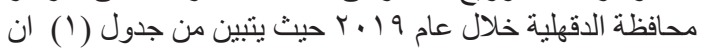

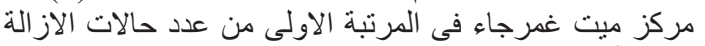

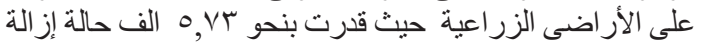

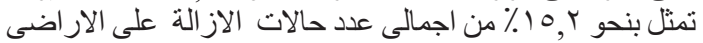

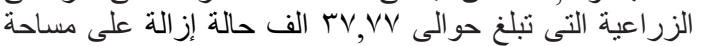

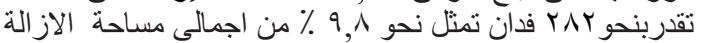

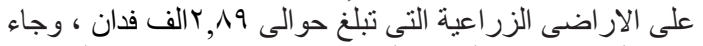

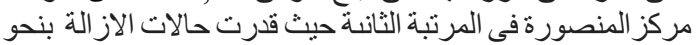

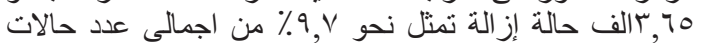

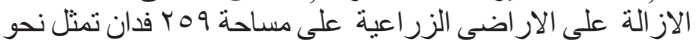

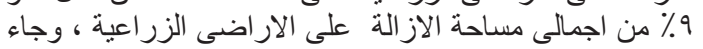

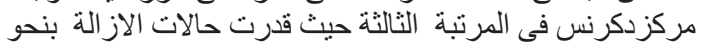

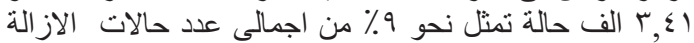

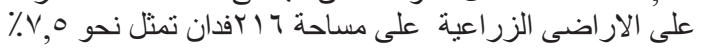

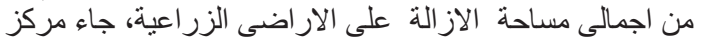

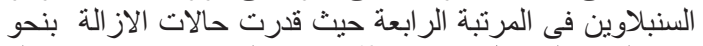

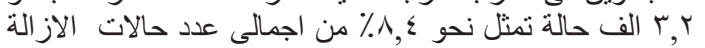

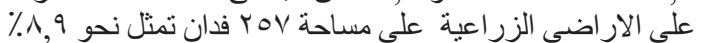

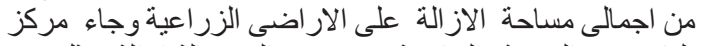

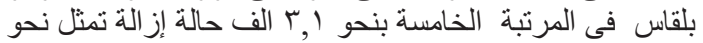

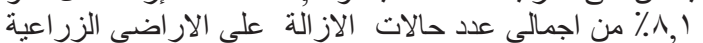

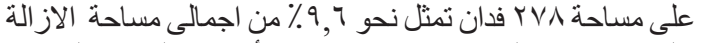

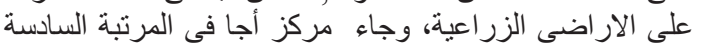

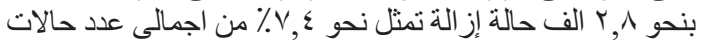

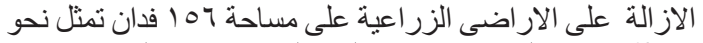

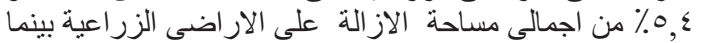
جاء مركز شربين في المرتبة السابعة حيث قدرت حالات الزئ الاز الة
السنبلاوين بصفة خاصة حتى يمكن تحقيق أهداف البحث سيتم

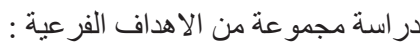

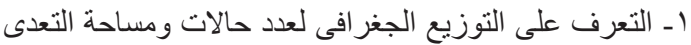

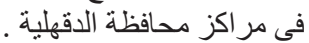

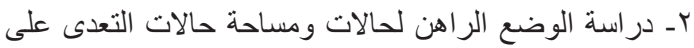
مستوى مر اكز وقرى محافطة الدقهلية بعينة البحث الميد العيدانية.

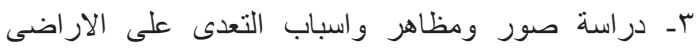
الزر اعية على الار اضى الزر اعية بالمحافظة.

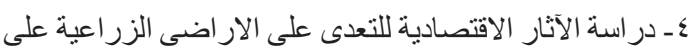

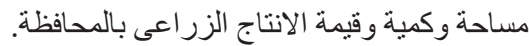

مصادر البيانات

يعتمد البحث علي مصدرين رئيسين للبيانات اولهما مصادر

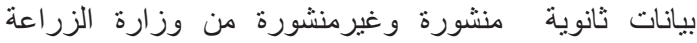

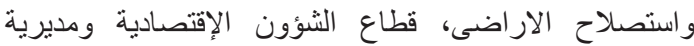

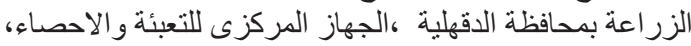

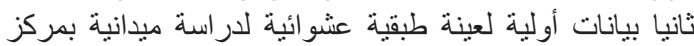

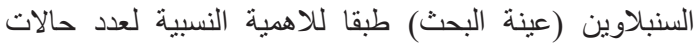

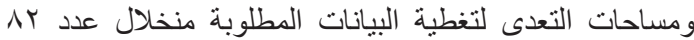

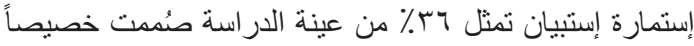

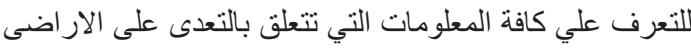
الزر اعية وتمت جميعها بالمقابلة الثخصية.

الطريقة البحثية

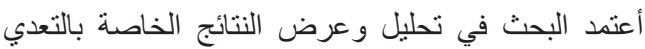

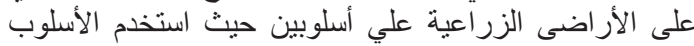

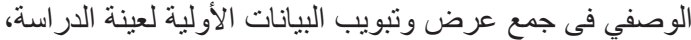

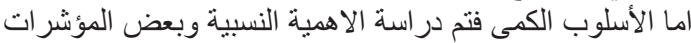
الاقتصادية و الاحصائية الخاصة برلية الإينة الدر اسة النة

طريقة سحب عينة البحث:

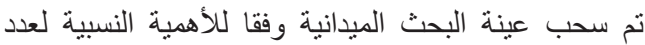

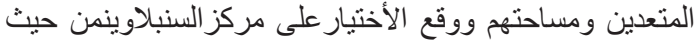

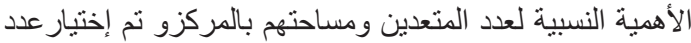

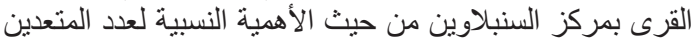

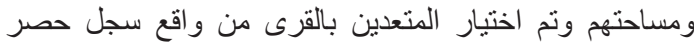

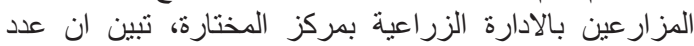

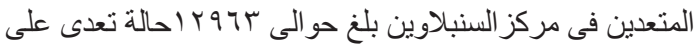

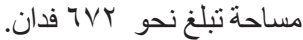

النتائج البحثية

أو لا: التوزيع الجغر افى لجملة حالات التعدى و مساحتها فى مر اكز

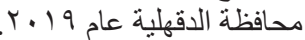

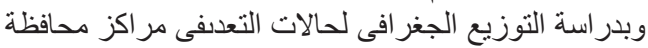

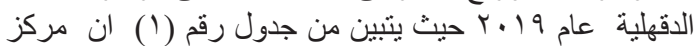

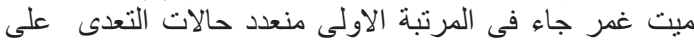

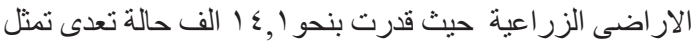

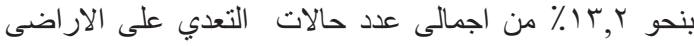

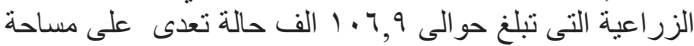

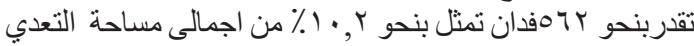

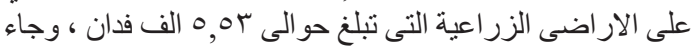

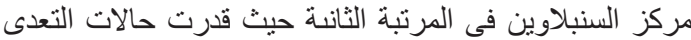

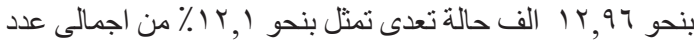

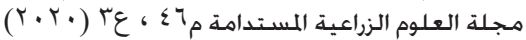


جدول ا ـ الاهمية النسبية لجملة التعديات و الازالات والباقى بدون ازالات ومساحتها فى مر اكز محافظة الدقهلية عام 9 1. ب

\begin{tabular}{|c|c|c|c|c|c|c|c|c|c|c|c|c|}
\hline \multicolumn{4}{|c|}{ الباقى بدون ازالة } & \multicolumn{4}{|c|}{ جملة الازالات } & \multicolumn{4}{|c|}{ جملة التعديات } & \\
\hline$\%$ & بالقدانة & $\%$ & حالات & $\%$ & بالفعديات & $\%$ & عدد حالات & $\%$ & التعديات & $\%$ & حالات & المركز \\
\hline 7,1 & 171 & 0,0 & $r \wedge . \wedge$ & $v, v$ & Trt & 7,1 & r.. & 7,9 & TAK & $0, v$ & $71 \cdot 1$ & طلذا \\
\hline 10,1 & $\varepsilon I V$ & $1 \leqslant, 1$ & 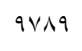 & $\wedge, 9$ & rov & $\wedge, \varepsilon$ & TIV & $M, Y$ & TVT & $1 Y, 1$ & שי & السنبلاو ين \\
\hline $1 \cdot, 7$ & rA. & $|r|$, & NזیI & $৭, \wedge$ & rAt & $10, r$ & OVTV & $1 \cdot, r$ & ort & $M, r$ & $1 \leq 1 \cdot 1$ & ميت غمر \\
\hline 9,9 & rut & $1 \cdot, 1$ & 7990 & १, & roq & $9, \mathrm{~V}$ & ryor & $q, \varepsilon$ & Ort & $1 \cdot$, & $1 \cdot 7 \leq 1$ & المنصورة \\
\hline$r$, & $\vee q$ & 0,0 & rVAr & 0,0 & 101 & 7, & rror & $\varepsilon, r$ & rte & $\varepsilon, v$ & $0 . r \leq$ & منية النصر \\
\hline$\varepsilon, \gamma$ & Trו & r,o & $r \leq \varepsilon r$ & $1, \wedge$ & or & $r, r$ & אזה & r, r & iv & r, & rrvo & ميت سويد \\
\hline $1,1-$ & rq_ & $\cdot, r$ & $r \leq r$ & $v, 0$ & YIT & 9, & $r \leq .0$ & $r, \varepsilon$ & INV & $r, \varepsilon$ & V & دكرنس \\
\hline 1,9 & $\leq 9$ & $1, v$ & Ir.o & $r, \tau$ & 1.0 & $r, q$ & $1 \leq 7 \pi$ & $r, \wedge$ & 100 & $r, \varepsilon$ & T471 & تمسالامديد \\
\hline$r, r_{-}$ & $7 .-$ & $r, 0$ & $1 \times 70$ & $\wedge, r$ & rrq & $0, r$ & 1974 & $r, r$ & 189 & $r, 0$ & TVTV & المنزلة \\
\hline$\varepsilon, \wedge$ & IrV & $7, r$ & $\leq Y q \leq$ & $0, \varepsilon$ & 107 & $v, \varepsilon$ & r^.. & 0,1 & tAT & $7, y$ & $V 19 \leq$ & 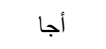 \\
\hline 11,9 & rio & $q, \varepsilon$ & $T \leq \wedge r$ & $v, r$ & $r \cdot q$ & $v, r$ & rVIt & $\mathrm{v}, \mathrm{v}$ & $\leq r \leq$ & $\wedge, 7$ & $919 \leq$ & شربين \\
\hline$\cdot, \wedge_{-}$ & $r \cdot-$ & $\varepsilon, \gamma$ & . & 9,7 & rVA & $\wedge, 1$ & $r \cdot v \wedge$ & $\varepsilon, V$ & roq & 7, & צั & بلقاس \\
\hline $7 \cdot, \wedge$ & 17.7 & $V \leqslant, 7$ & $0171 \mathrm{~V}$ & $\wedge \varepsilon, 1$ & $r \leq T$ & $\wedge \wedge, r$ & דצזrז & $V^{\prime}$, & $\varepsilon \cdot r \wedge$ & $v_{q}, \varepsilon$ & Аะดтr & الائتمان \\
\hline$r \leqslant, q$ & GrY & $r \leq$, & $1701 \mathrm{r}$ & $10, r$ & $\varepsilon r q$ & $11, r$ & ETTK & $r \leqslant, 7$ & & 19,0 & $r \cdot \lambda \leq 0$ & الاصماح الى \\
\hline$\varepsilon, r$ & 11. & 1,0 & 1.19 & $\cdot, \mathrm{V}$ & 19 & $\cdot, \varepsilon$ & 109 & $r, r$ & 149 & 1,1 & $11 \mathrm{VA}$ & الجمالى العبة \\
\hline $1 \cdots$, & rTs. & $1 \cdots$, & 79Y11 & $1 \cdots$, & $r \wedge \wedge 9$ & $1 \cdots$, & rVVTA & $1 \cdots$, & oork & $1 \cdots$, & 1.7917 & المحافلى \\
\hline
\end{tabular}

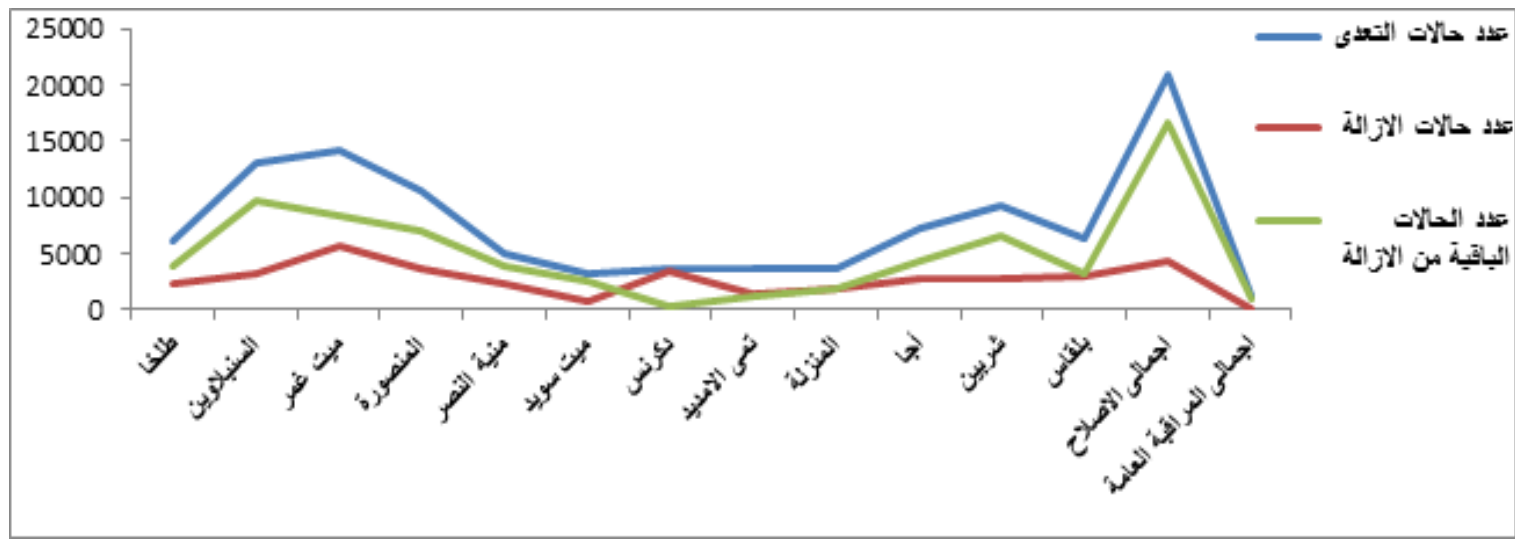

شكل 1. عدد حالات التعديات و الازالات والباقى بلون ازالات فى مراكز محافظة الدقهلية 9 ا ـ ب

الصصدر : جدول (T)

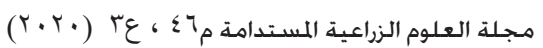




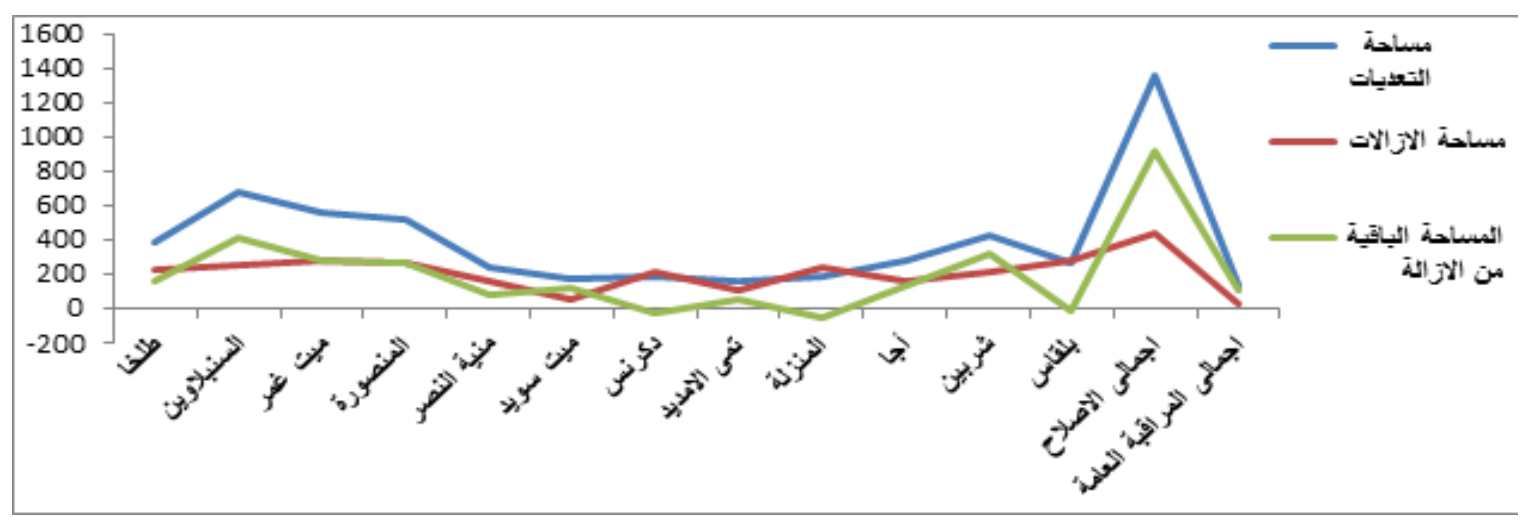

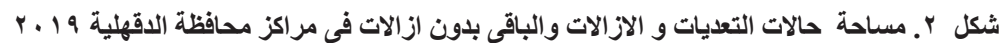

(†) (المصدر : جدول رقم

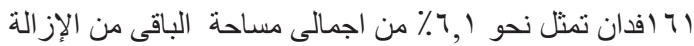

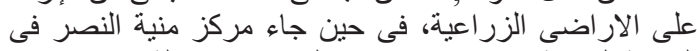

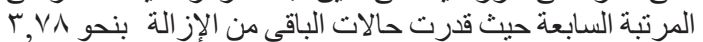

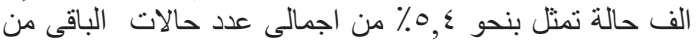

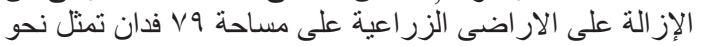

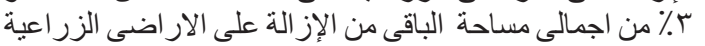

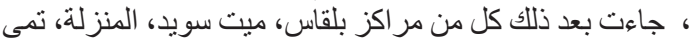

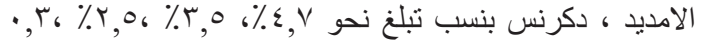

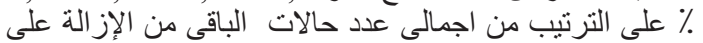

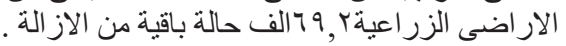

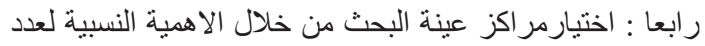

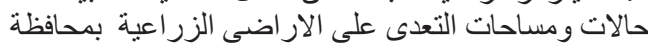

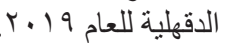

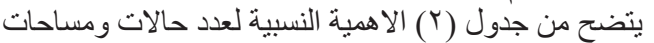

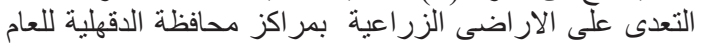

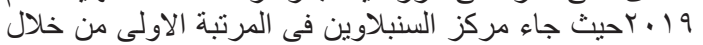

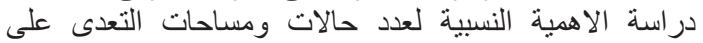

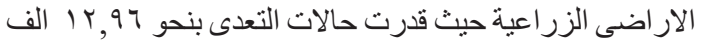

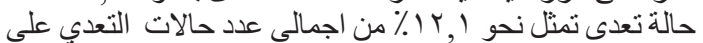

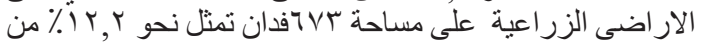

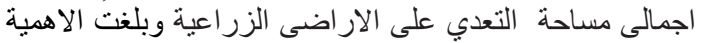

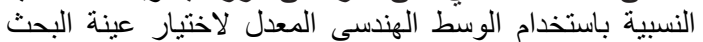

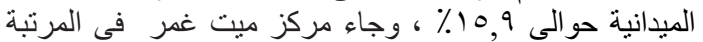

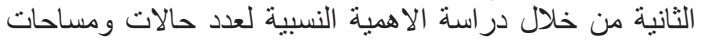

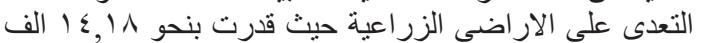

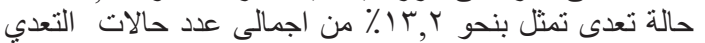

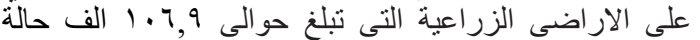

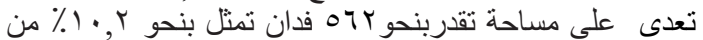

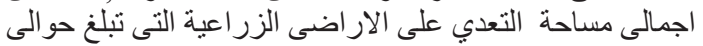

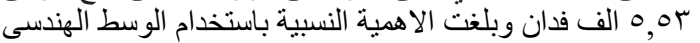

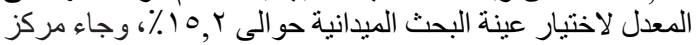

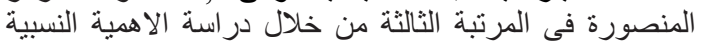

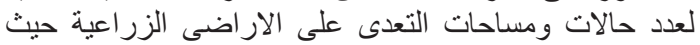

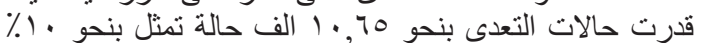

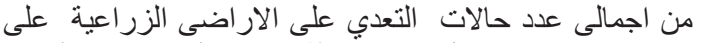

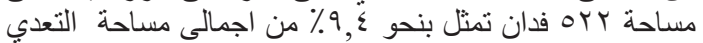

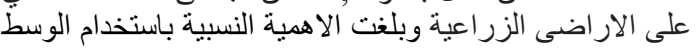

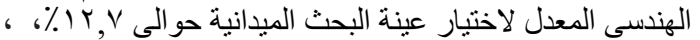

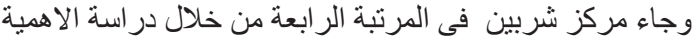

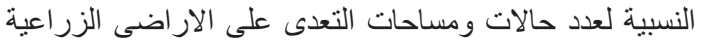

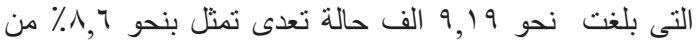
اجمالى عدد حالات التعدي على الار اضى الزعى الزية على مساحة

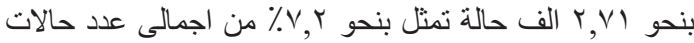

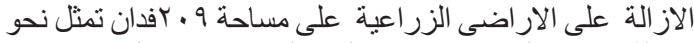

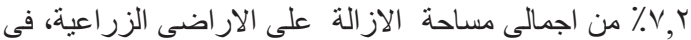

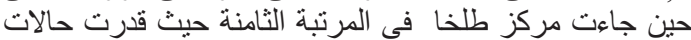

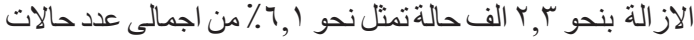

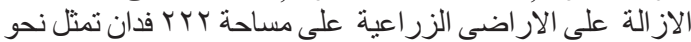

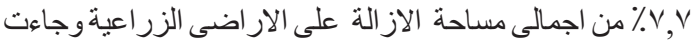

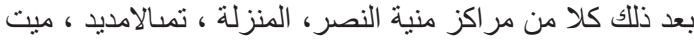

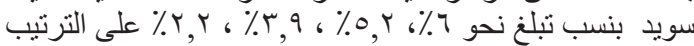

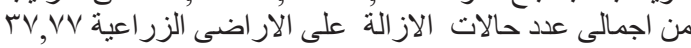

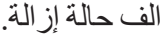

ثالثا: التوزيع الجغر افى لحالات الباقى من الإز الة و ومساحتها فى لـى

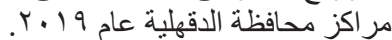

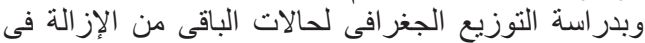

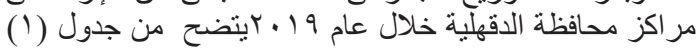

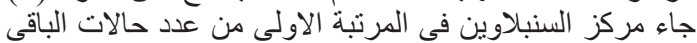

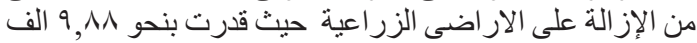

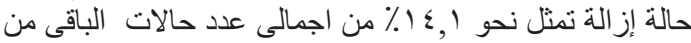

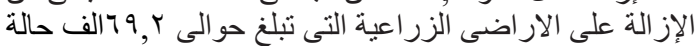

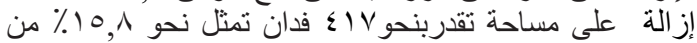

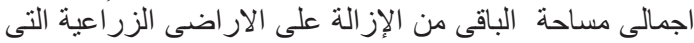

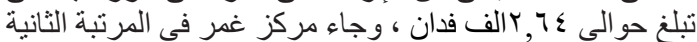

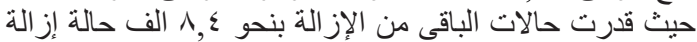

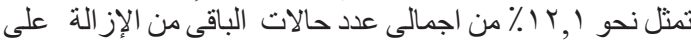

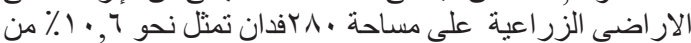

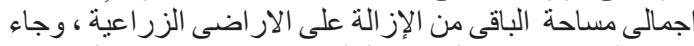

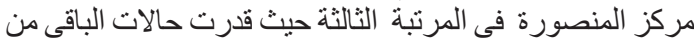

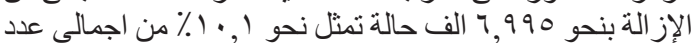

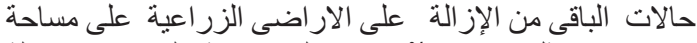

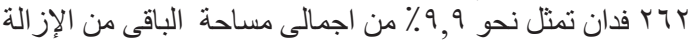

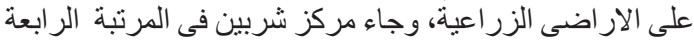

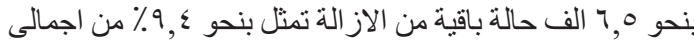

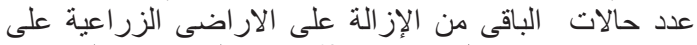

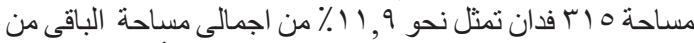

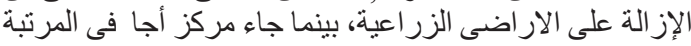

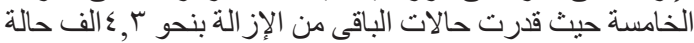

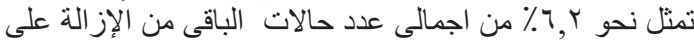

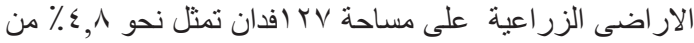

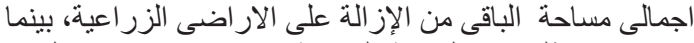

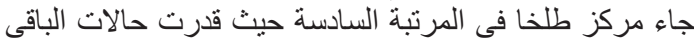

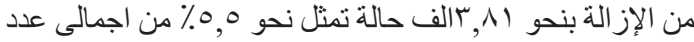

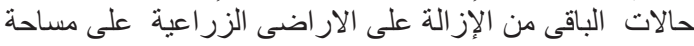

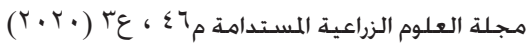


النسبية للقرى بالمركز. الهنسى المعدل من حيث الاعلى فى الاهمية

(الوسط الهندسى: هو نوع من المتوسطات أو المعدلات التى تقبس

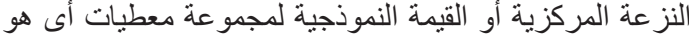

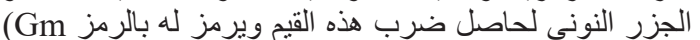

( Moussa,1989)

خامسا: اختيار قرى عينة البحث من خلال الاهمية النسبية لعدد حالات ومساحات التعدى على الار اضى الزئي الزراعية بمركز

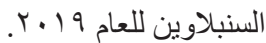

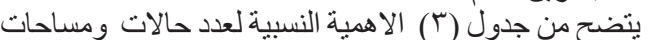

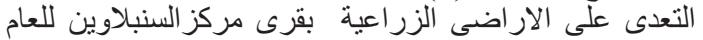

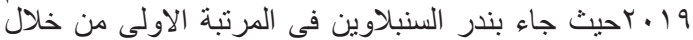

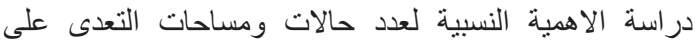

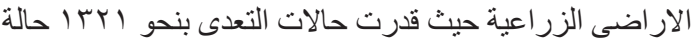

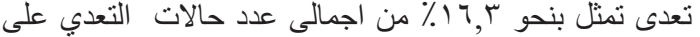

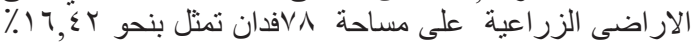

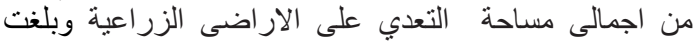

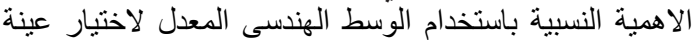

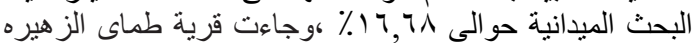

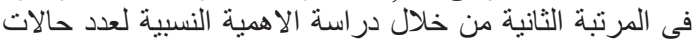

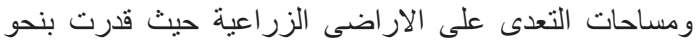

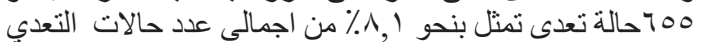

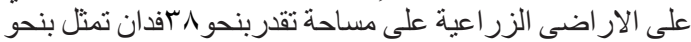

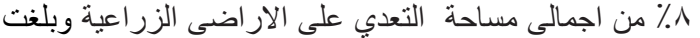

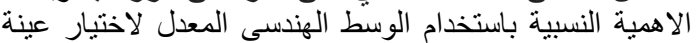

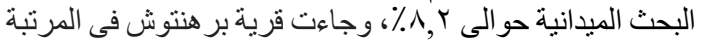

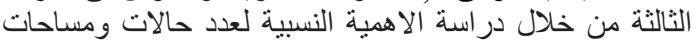
التعدى على الار اضى الزر اعية حيث قدرت حالات التعدى بنحو

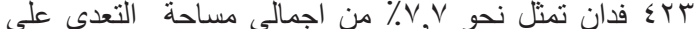

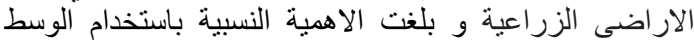

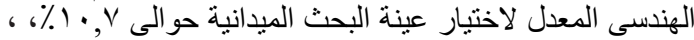

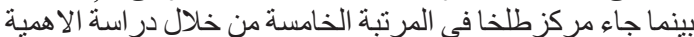

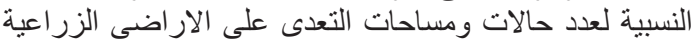

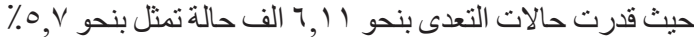

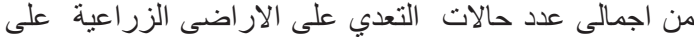

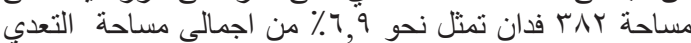

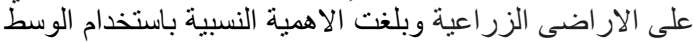

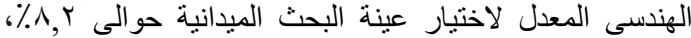

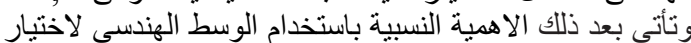

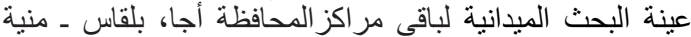

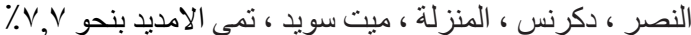

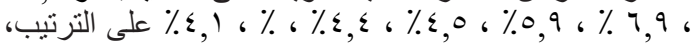
وطبقا لما سبق سوف يقوم الباحث باختيار أهم مركز من مر عراكز

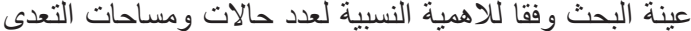

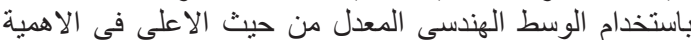

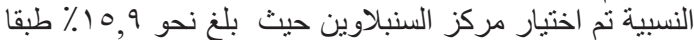

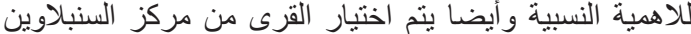

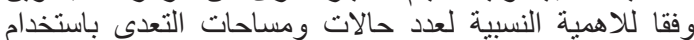

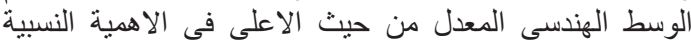

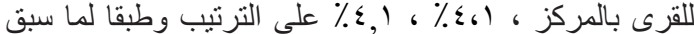

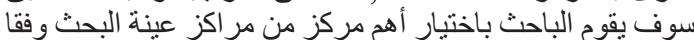

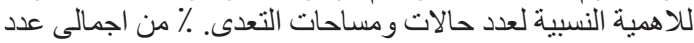

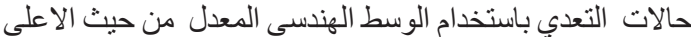

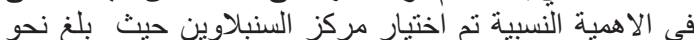

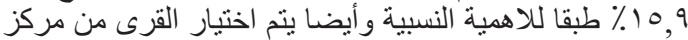
السنبلاوين وفقا للاهمية النسبية لعدد حالات ومساحات النعدى النيخ

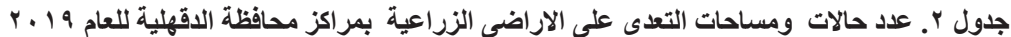

\begin{tabular}{|c|c|c|c|c|c|c|}
\hline الوسط الهندسى & الوسط الهندسى & $\%$ & مساحة التعديات & $\%$ & عدلد حالات & المركز \\
\hline$\wedge, r$ & $7, r$ & 7,9 & rAt & $0, V$ & $7 \cdot 1$ & طلذا \\
\hline 10,9 & $1 r_{,}$ & $M, r$ & TRT & $r_{,} 1$ & איז & السنبلاوين \\
\hline $10, r$ & 11,7 & $1 \cdot, r$ & OTr & Ir, & $1 \leqslant 1 \cdot 1$ & ميت غمر \\
\hline Ir, & $9, \vee$ & $9, \varepsilon$ & Ort & $1 \cdot, \cdot$ & $1 \cdot 7 \leqslant 1$ & المنصورة \\
\hline 0,9 & $\varepsilon, 0$ & $\varepsilon, r$ & rTV & $\varepsilon, V$ & $0 . r \varepsilon$ & منية النصر \\
\hline$\varepsilon, 1$ & $r, 1$ & $r, r$ & $1 V 4$ & $r, 1$ & revo & ميت سويد \\
\hline$\varepsilon, 0$ & $r, \varepsilon$ & $r, \varepsilon$ & IAV & $r, \varepsilon$ & $r 4 \leqslant V$ & دكرنس \\
\hline$\varepsilon, 1$ & $r, 1$ & $r, \wedge$ & 100 & $r, \varepsilon$ & rדז1 & تمى الامديد \\
\hline$\varepsilon, \varepsilon$ & $r, \varepsilon$ & $r, r$ & $1 \times 9$ & $r, 0$ & TVYV & المنزلة \\
\hline $\mathrm{v}, \mathrm{V}$ & 0,9 & 0,1 & rNT & $7, Y$ & V) $9 \leqslant$ & أجا \\
\hline $1 \cdot, \mathrm{V}$ & $\wedge, 1$ & $v, v$ & $\varepsilon r \leqslant$ & $\wedge, 7$ & $919 \leqslant$ & 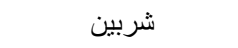 \\
\hline 7,9 & $0, r$ & $\varepsilon, V$ & roq & $\uparrow, \cdot$ & 7 & بلقاس \\
\hline \multirow{4}{*}{$1 \cdots}$, & \multirow{4}{*}{$07, \mathrm{~V}$} & $V r, \cdot$ & $\varepsilon \cdot r \wedge$ & $v q, \varepsilon$ & $\lambda \leqslant 97 r$ & اجمالى الائتمان \\
\hline & & $r \leqslant, T$ & אידואו & 19,0 & $r \cdot \wedge \leq 0$ & اجمالى الاصلاح \\
\hline & & $r, r$ & 149 & 1,1 & $11 \mathrm{VA}$ & اجمالى المر اقبة العامة \\
\hline & & $1 \ldots$ & $00 Y \wedge$ & $1 \ldots$ & 1.7917 & اجمالى المحافظة \\
\hline
\end{tabular}

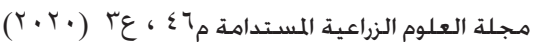




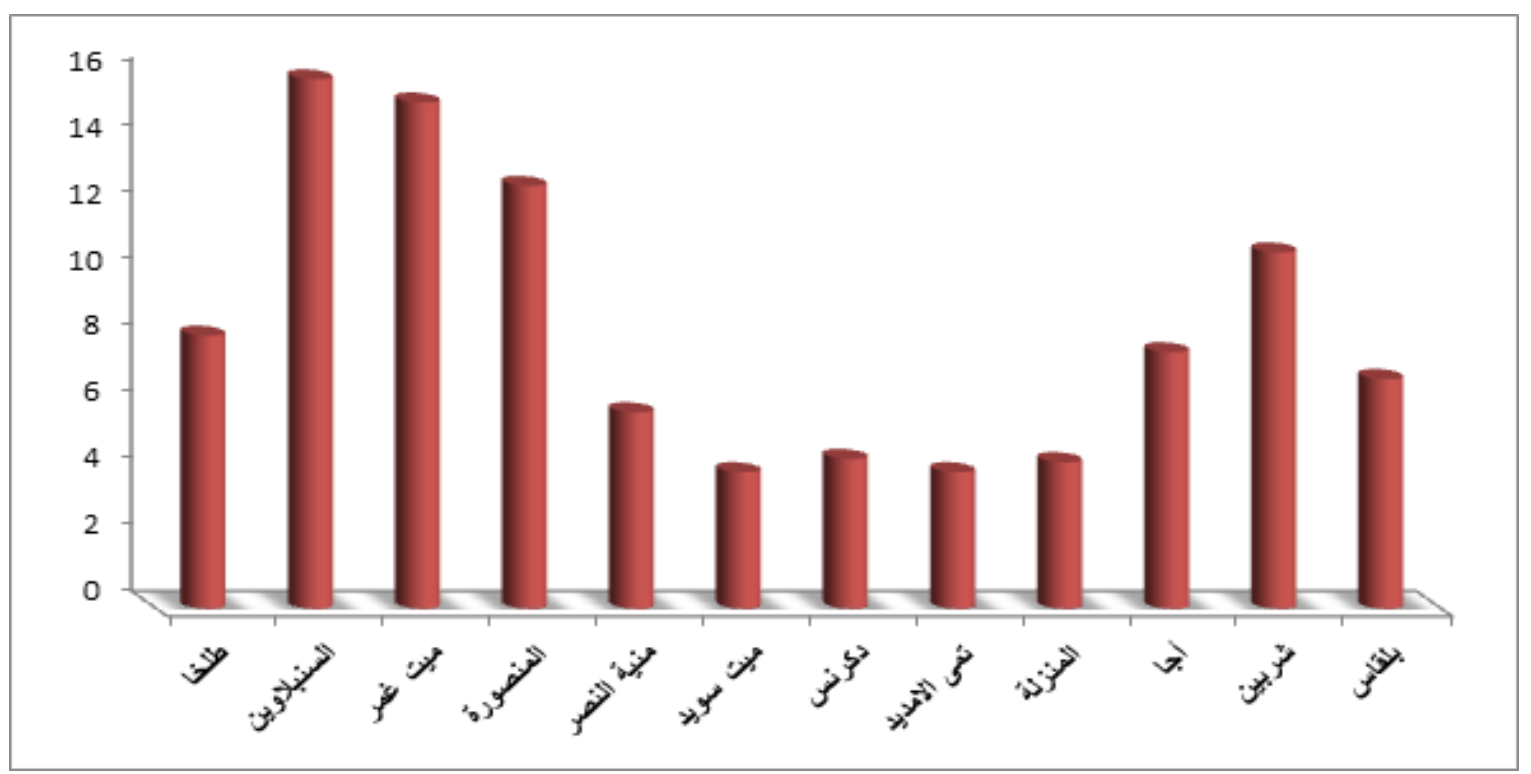

شكل r. التوزيع النسبى لمراكز عينة البحث بمحافظة الدقهلية

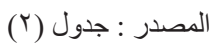

عدد 9 مشاهدة و يتضح من جدول r إ أقسيم المساحة المتعدى عليها

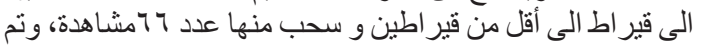

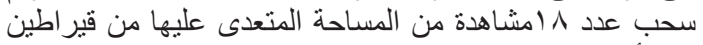

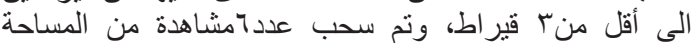

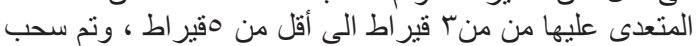

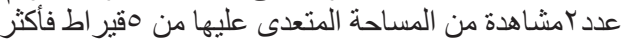

سادسا : صور التعدى على الاراضى الزراعية فى قرى عينة

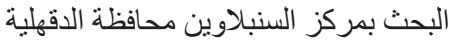

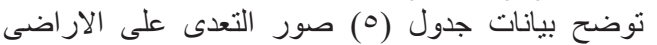

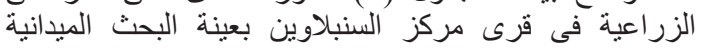

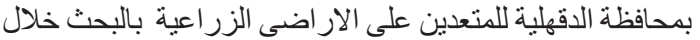

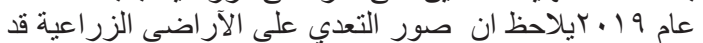
أخذت عدة صور و وأنماط مختلفة تم حصر ها في ستخة أنماط هي الزي كما يلي : اخذ عد:

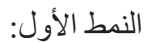

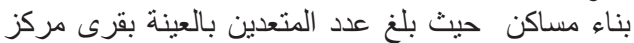

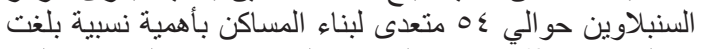

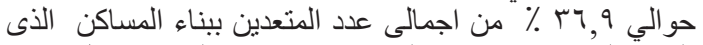

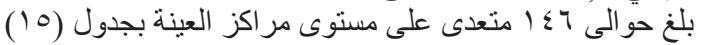

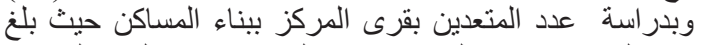

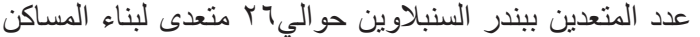

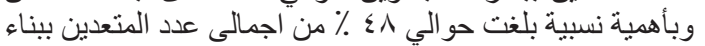

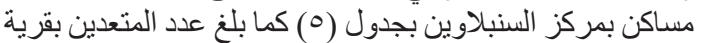

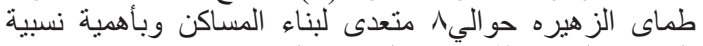

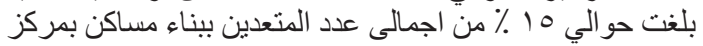

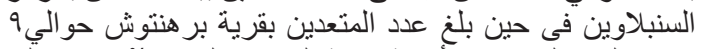

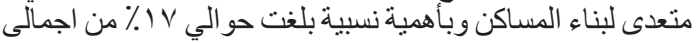

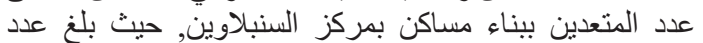

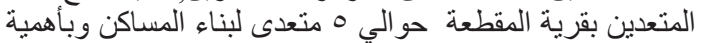

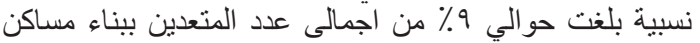

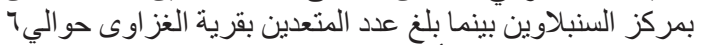

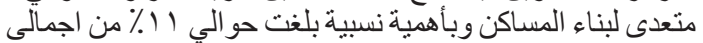
عدد المتعدين ببناء مساكن بمركز السنبلاوين.

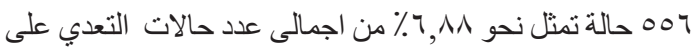

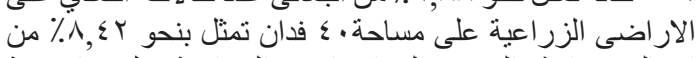

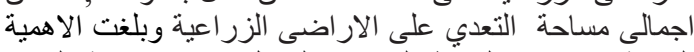

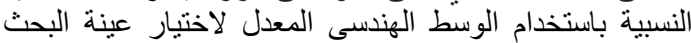

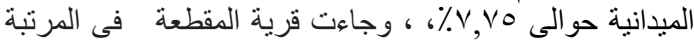

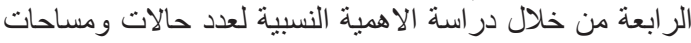

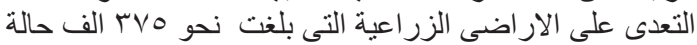

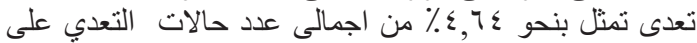

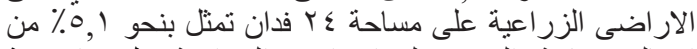

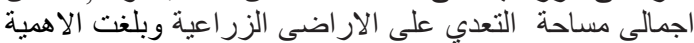

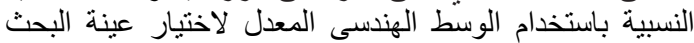

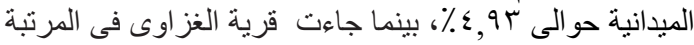

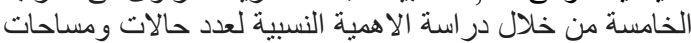

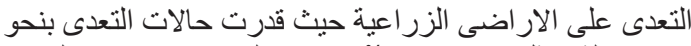

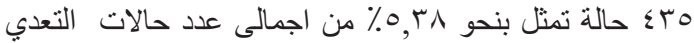

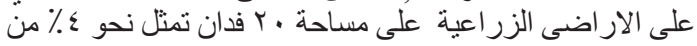

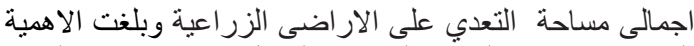

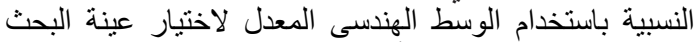

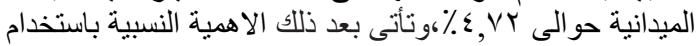

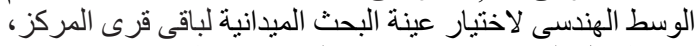

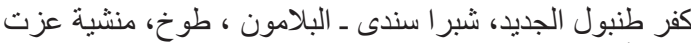

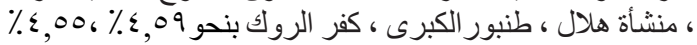

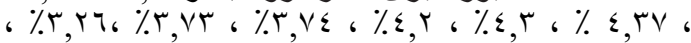

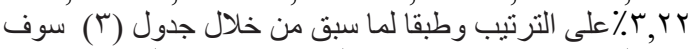

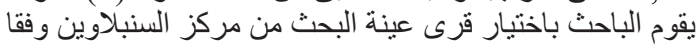

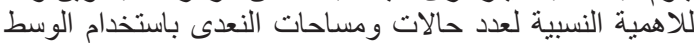

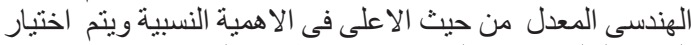

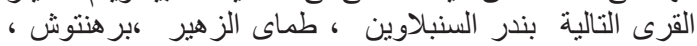

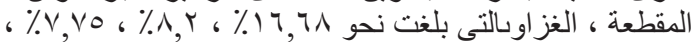

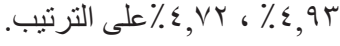

يتضح من جدول (ع ) طبقا لتوزيع حجم العينة الطبقية وفقا

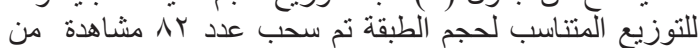

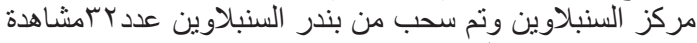

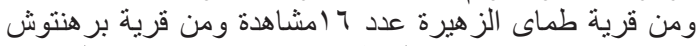

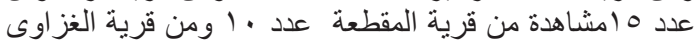


جدول r. عدد حالات ومساحات التعدى على الاراضى الزراعية بقرى مركز السنبلاوين بمحافظة الدقهلية للعام 9 1. ب

\begin{tabular}{|c|c|c|c|c|c|c|c|}
\hline \multirow[t]{2}{*}{ الوسط الهندسى المعدل } & \multirow[t]{2}{*}{ الوسط الهندسى } & & \multicolumn{2}{|c|}{ مساحة التعديات } & \multirow[b]{2}{*}{$\%$} & \multirow[t]{2}{*}{ عدد التعديات } & \multirow[t]{2}{*}{ القرية } \\
\hline & & $\%$ & ف & b & & & \\
\hline 17,71 & rY, & $17, \leqslant Y$ & $\vee \wedge$ & 11 & سז, 17 & ITYI & بندر السنبلاوين \\
\hline$\wedge, r$. & $10 \mathrm{~V}, 1$ & $\wedge, \cdots$ & rᄉ & 0 & $\wedge, 1$. & 700 & طمانالز هيره \\
\hline V, vo & $1 \leq 9,1$ & $\Lambda, \leqslant r$ & $\varepsilon$. & 9 & $7, \wedge \wedge$ & 007 & بر هنتوش \\
\hline$\varepsilon, \leqslant 7$ & $\wedge 0, \wedge$ & $r, 0 \wedge$ & iv & 11 & $0, T_{0}$ & \&rr & الز هيره \\
\hline$\varepsilon, \mu$ & $\wedge r, \wedge$ & $r, r v$ & 17 & r) & $0, \mu$. & $\varepsilon r q$ & الحصبتة \\
\hline$\varepsilon, V Y$ & $9 \cdot, 9$ & $\varepsilon, \cdots$ & 19 & YI & $0, \Gamma \wedge$ & sto & الغز اوى \\
\hline$\varepsilon, 9 \pi$ & $9 \leq, 9$ & 0,0 & $r \leq$ & 10 & $\varepsilon, 7 \varepsilon$ & rvo & المقطعة \\
\hline$\varepsilon, 09$ & $\wedge \wedge, \mu$ & $\varepsilon, \varepsilon r$ & YI & 0 & $\varepsilon, 09$ & rvi & كفر طنبول الجديد \\
\hline$\varepsilon, Y$. & $\wedge \cdot, \wedge$ & $r, v q$ & 11 & 1 & $\varepsilon, \leqslant 9$ & אדי & طوخ \\
\hline$\varepsilon, \Gamma V$ & $\wedge \varepsilon, 1$ & $\varepsilon, r_{1}$ & $r$. & IV & $\varepsilon, \Gamma \wedge$ & Tos & البلامون \\
\hline$\varepsilon, \infty$ & $\Lambda V, 0$ & $\varepsilon, \wedge \varepsilon$ & r & r & $\varepsilon, 1 r$ & אזr & شبر ا سندى \\
\hline$r, v \varepsilon$ & $V r, \cdot$ & $r, r v$ & 17 & IV & $\varepsilon,+1$ & rTs & منشية عزت \\
\hline r, Ir & $7 .$, & r,or & ir & ir & $r, v i$ & r.. & الجلايلة \\
\hline r, & VI,, & $r, v q$ & 11 & r & $r, 0 \leqslant$ & rᄉT & منشأة هلال \\
\hline$r, r$ & $T r$, & $r, 17$ & 10 & iv & T,IV & Yor & كفر الروك \\
\hline דr, & $T r, \Lambda$ & $r, v q$ & 11 & $\wedge$ & $r, V_{1}$ & Y19 & طنبور الكبرى \\
\hline$r, r$. & $\varepsilon \leqslant, \Gamma$ & $1, \wedge 9$ & 9 & YI & $r, v$. & Y1A & غز الة \\
\hline r, IV & 71, & $r, v q$ & 11 & Ir & r,or & $r \cdot v$ & برقين \\
\hline r,or & $\varepsilon \wedge, V$ & r,or & Ir & 0 & $r, \leq 0$ & 191 & بشميس \\
\hline$r, 0$. & $\varepsilon \wedge, 1$ & r,or & IT & $1 \varepsilon$ & $r, r q$ & 194 & الحصوة \\
\hline $1,7$. & $r \cdot, q$ & 1,71 & $\wedge$ & 0 & $1, \varepsilon V$ & 119 & كفر يوسف \\
\hline rד, & 0,7 & $r, v q$ & 11 & ir & $1, \vee 7$ & $1 \leq Y$ & ميت غراب \\
\hline \multirow{2}{*}{$1 \cdots$} & \multirow{2}{*}{1940} & & $19 V$ & & & $\{\wedge \vee \uparrow$ & اخرى \\
\hline & & & TVY & & & אד & الاجمالى \\
\hline
\end{tabular}

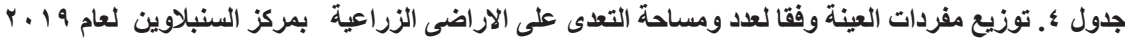

\begin{tabular}{|c|c|c|c|c|c|}
\hline \multicolumn{4}{|c|}{ المساحة المتعدى عليها } & \multirow[b]{2}{*}{ قدرية المشاهدات لكل } & \multirow[b]{2}{*}{ القرية } \\
\hline هقير اط فاكثر & بقير اط الحى اقل من & قير اطين الى أقل من & قير اط الى أقل من & & \\
\hline 1 & r & v & rt & rt & بندر السنبلاوين \\
\hline - & r & 7 & $\wedge$ & 17 & طمانالز هيره \\
\hline 1 & r & r & 9 & 10 & بر هنتوش \\
\hline- & - & 1 & 9 & 1. & المقطعة \\
\hline- & - & 1 & $\wedge$ & 9 & الغز اوى \\
\hline r & 7 & 11 & 77 & NT & الجملة \\
\hline
\end{tabular}

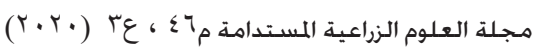




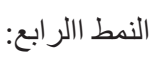

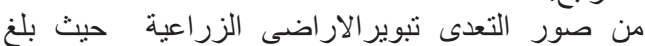

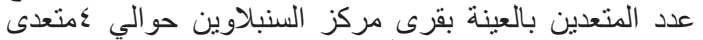

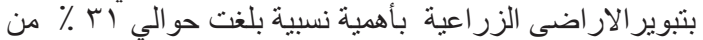

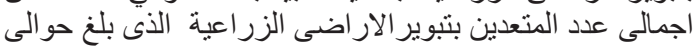

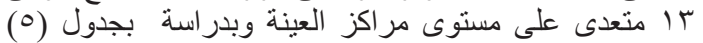

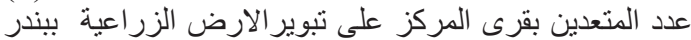

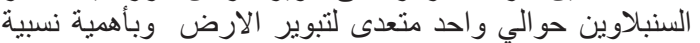

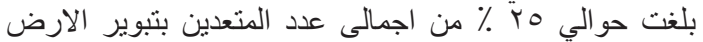

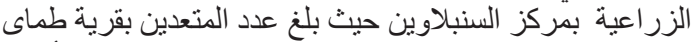

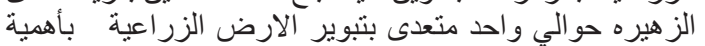

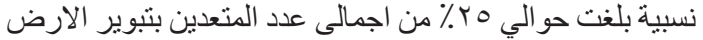

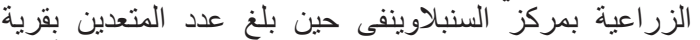

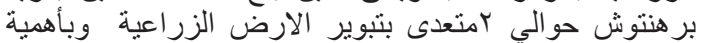

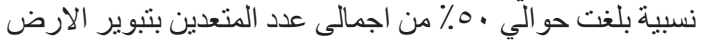
الزر اعية بمركز السنبلاوين.

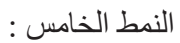

تشوين مو اد البناء حيث بلغ عدد المتعدين بالعينة بقرى مركز

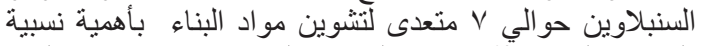

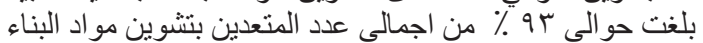

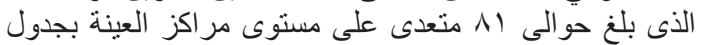

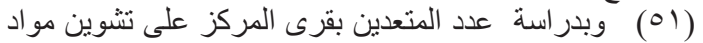

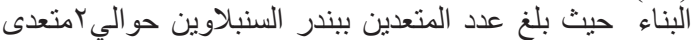

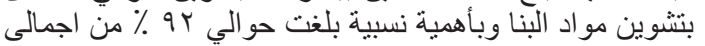

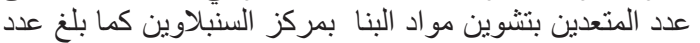

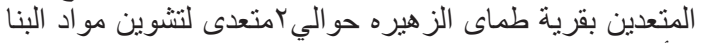

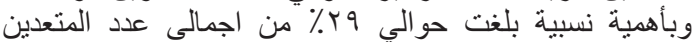

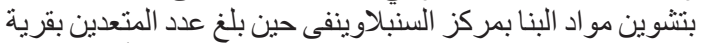

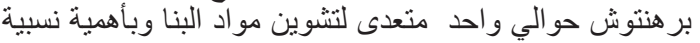

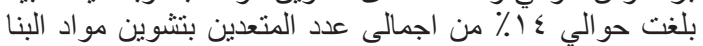

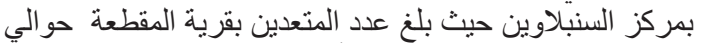

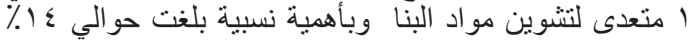

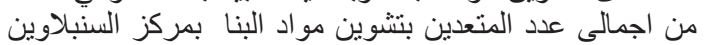

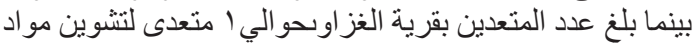

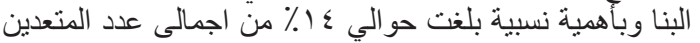
بتشوين مواد البنا بمركز السنبلاًّين. بلغي

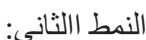

من صور التعدى بناء مزارع (تسمين دواجن) حيث بلغ العزئ

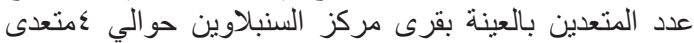

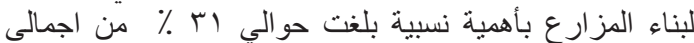

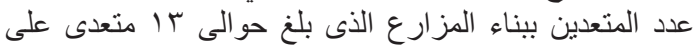

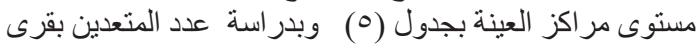

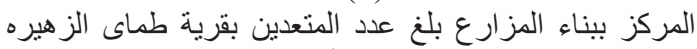

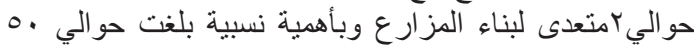

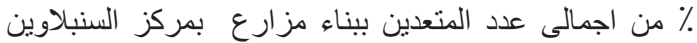

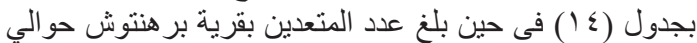

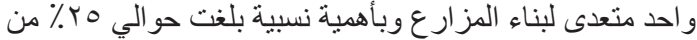

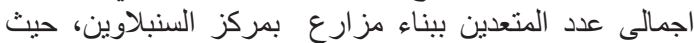

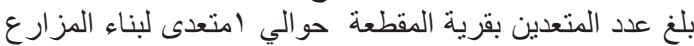

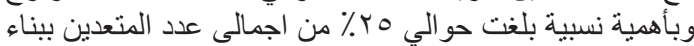
مزارع بمركز السنبلاوين.

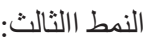

من صور التعدى بناء ورش حيث بلغ عدد المتعدين بالعينة

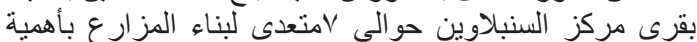

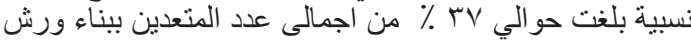

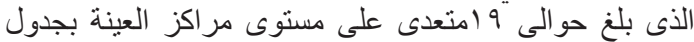

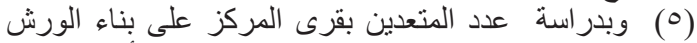

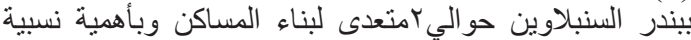

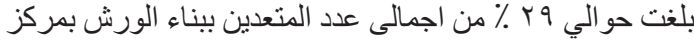

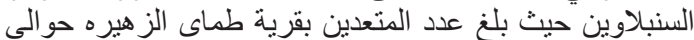

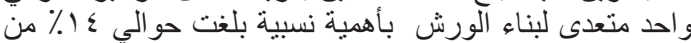

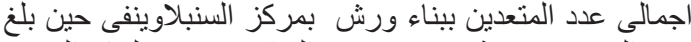

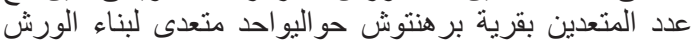

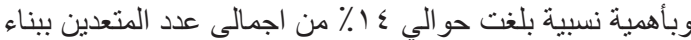

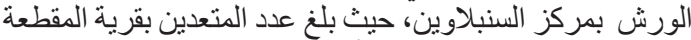

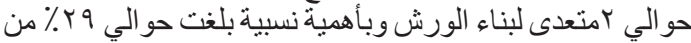

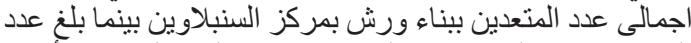

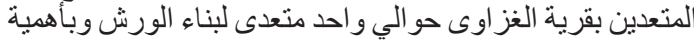

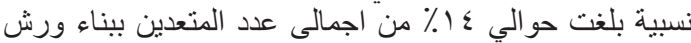

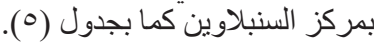

جدول ه. صور التعدى على الاراضى الزراعية فى قرى عيتة|لبحث بمراكز محافظة الدقهلية

\begin{tabular}{|c|c|c|c|c|c|c|c|c|c|c|c|c|c|c|c|}
\hline$\%$ & \{ & $\%$ & $\begin{array}{l}\overline{3} \\
3 \\
a \\
\text { â. } \\
\text { g. }\end{array}$ & $\%$ & $\begin{array}{l}3 \\
3 \\
3 \\
3 \\
\frac{3}{3}\end{array}$ & $\%$ & 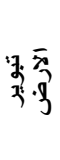 & $\%$ & से & $\%$ & 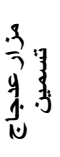 & $\%$ & $\begin{array}{l}]^{\circ} \\
\text { a } \\
3 \\
3 \\
3\end{array}$ & 司 & पे \\
\hline 0 & & 20 & 1 & 29 & 2 & 25 & 1 & 0,29 & 2 & 0 & 0 & 48 & 26 & بندر السنبلاوين & \multirow{5}{*}{$\begin{array}{l}\overline{7} \\
\text { 年 } \\
3 \\
3\end{array}$} \\
\hline 100 & 1 & 20 & 1 & 29 & 2 & 25 & 1 & 0,14 & 1 & 50 & 2 & 15 & 8 & طمانالزهيره & \\
\hline 0 & 0 & 20 & 1 & 14 & 1 & 50 & 2 & 0,14 & 1 & 25 & 1 & 17 & 9 & برهتوش & \\
\hline 0 & 0 & 20 & 1 & 14 & 1 & 0 & 0 & 0,29 & 2 & 25 & 1 & 9 & 5 & المقطعة & \\
\hline 0 & & 20 & 1 & 14 & 1 & 0 & 0 & 0,14 & 1 & 0 & 0 & 11 & 6 & الغزاوى & \\
\hline 100 & 1 & 100 & 5 & 100 & 7 & 100 & 4 & 100 & 7 & 100 & 4 & 100 & 54 & & \\
\hline
\end{tabular}

المصدر : جمعت وحسبت من بيانات عينة البحث الميدانية بمحافظة الدقهلية

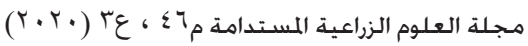


إز الة التعديات علي الأرض الزراعية بأهمية نسبية بلغت حوالي الئي

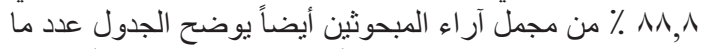

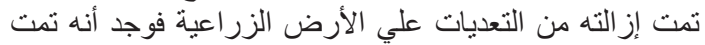

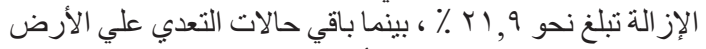

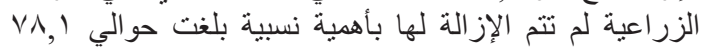

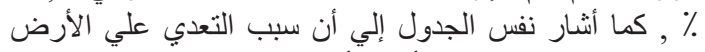

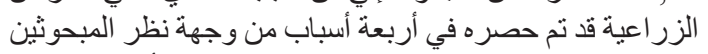

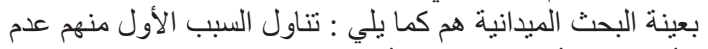

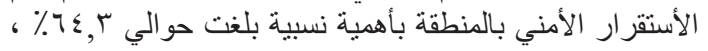

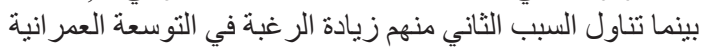

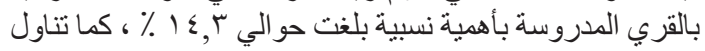

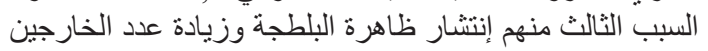

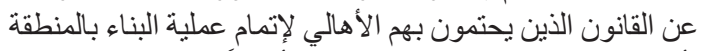

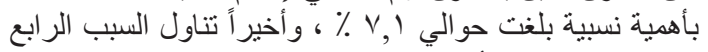

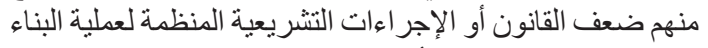

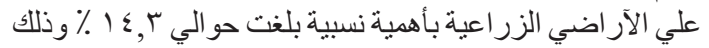

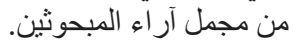

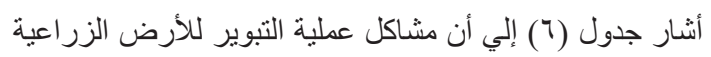

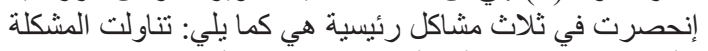

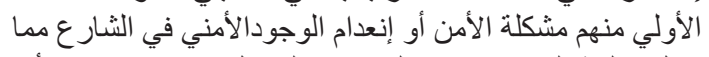

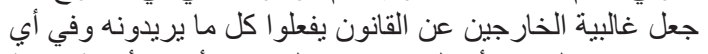

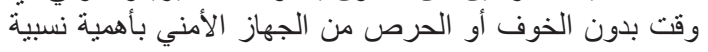

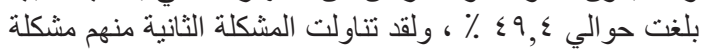

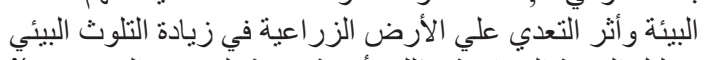

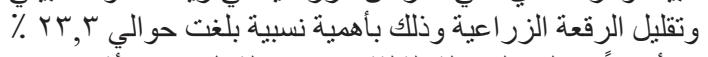

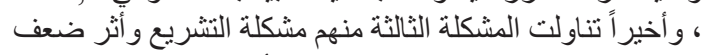

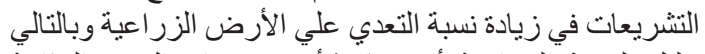

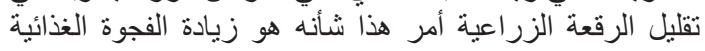

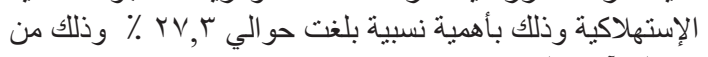
إجمالي آراء المبحوثين.

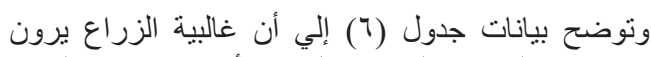

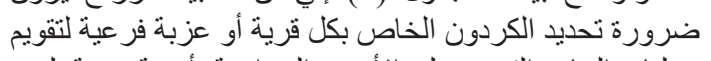

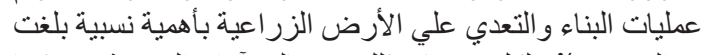

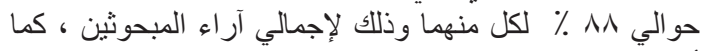

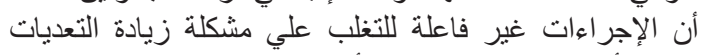

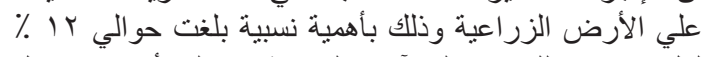

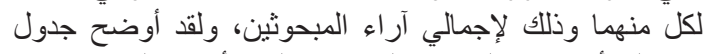

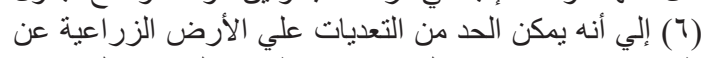

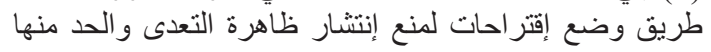

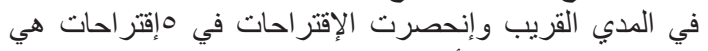

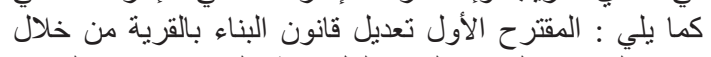

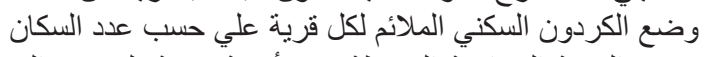

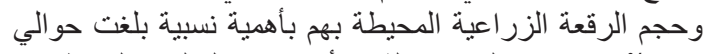

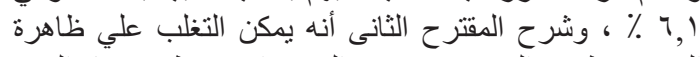

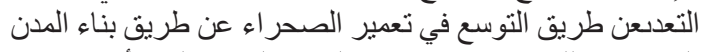

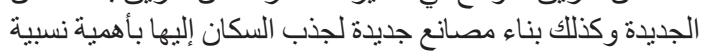

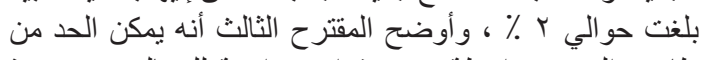

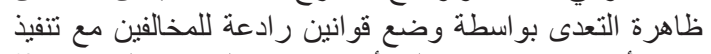

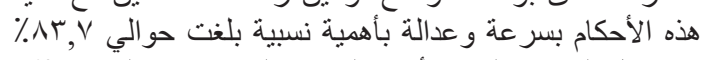

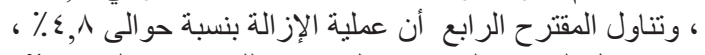

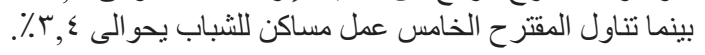

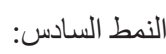
انثاء ملاعب حيث بلغ عدأ المتعدين بالعينة بقرى مركز

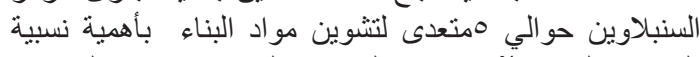

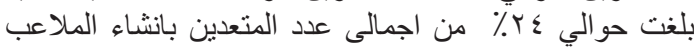

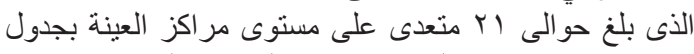

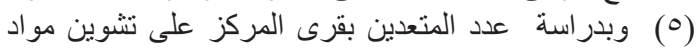

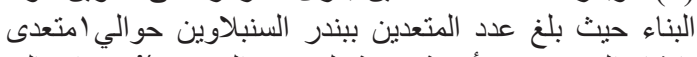

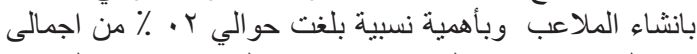

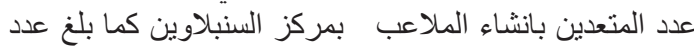

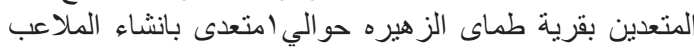

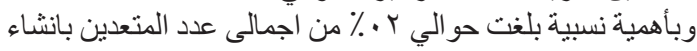

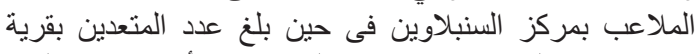

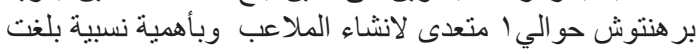

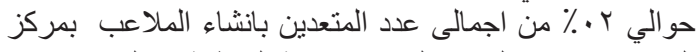

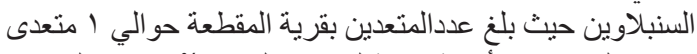

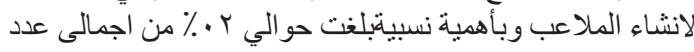

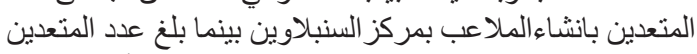

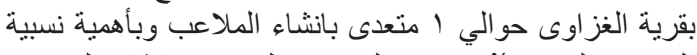

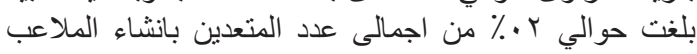

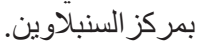

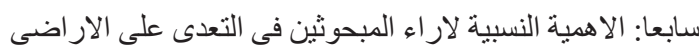

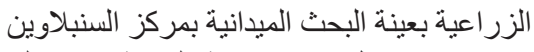

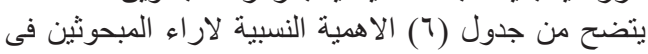

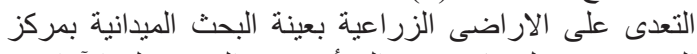

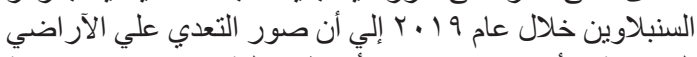

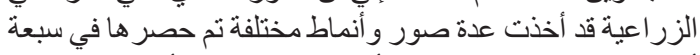

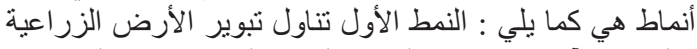

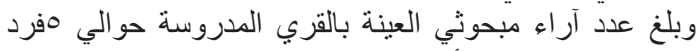

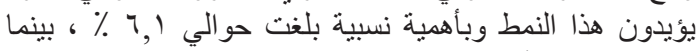

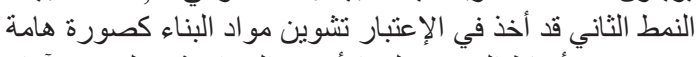
من صور وأنماط التعدي علي الأرض الزبر الزر اعية وييلغ عدد آراء

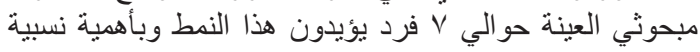

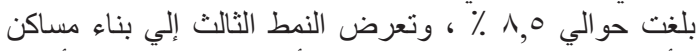

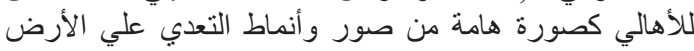

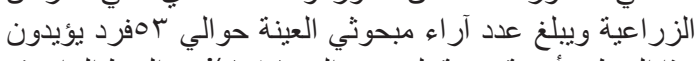

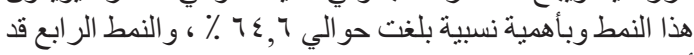

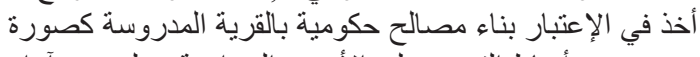

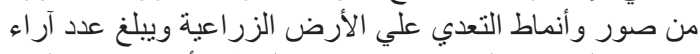

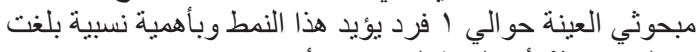

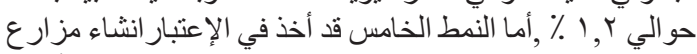

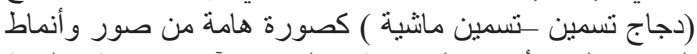

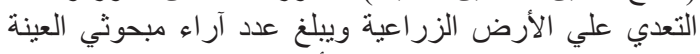

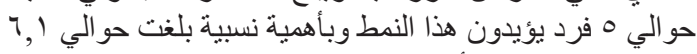

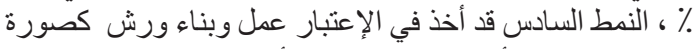

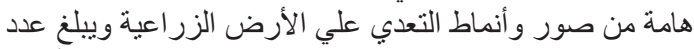

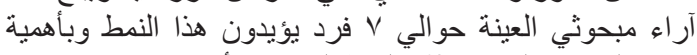

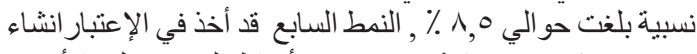

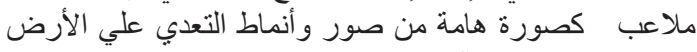

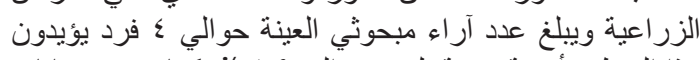

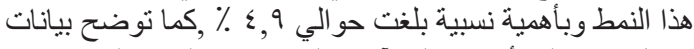

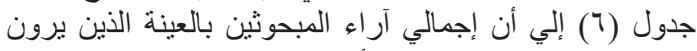

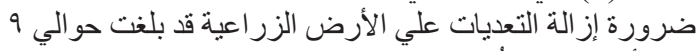

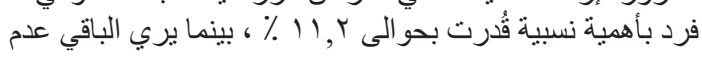


حث المزارعين علي التمسك بالأرض الزر اعية كمورد إقتصادي لبادي

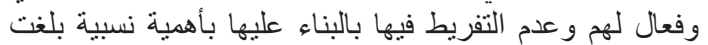

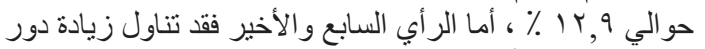

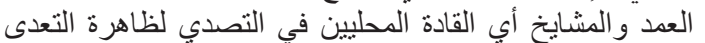

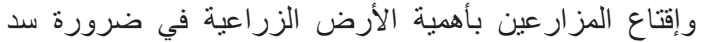

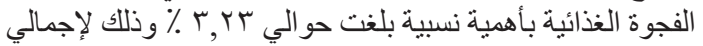

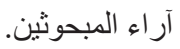

ويوضح جدول (V) رأي مدير الحماية في التصدي لظاهرة

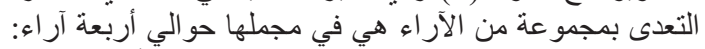

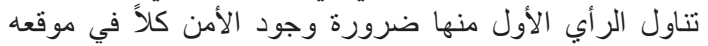

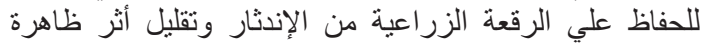

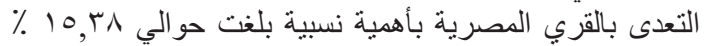

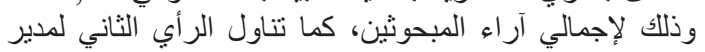

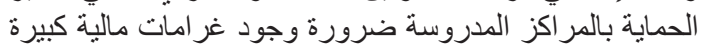

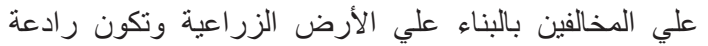

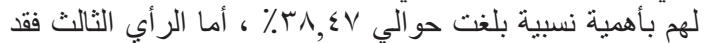

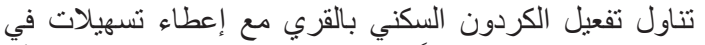

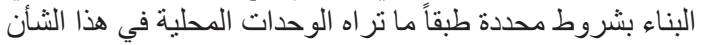

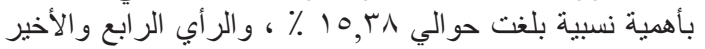

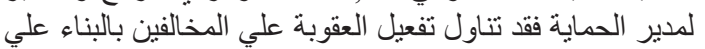

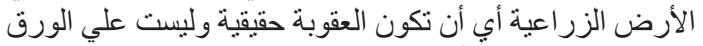

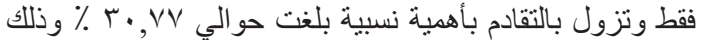

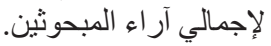

ثامنا : الأهمية النسبية لآراء مدير الجمعية ومدير الحماية ورجال الإدارة وسكان القرى بعينة البحث الميدانية بمركز

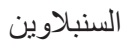

وتثثير بيانات جدول رقم (V) الى لأهمية النسبية لآراء

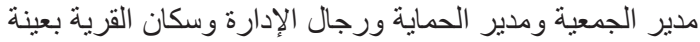

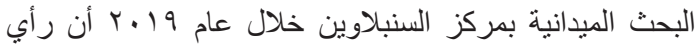

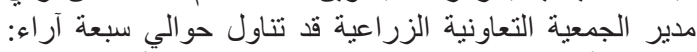

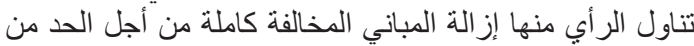

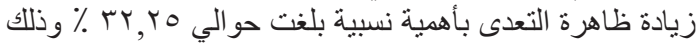

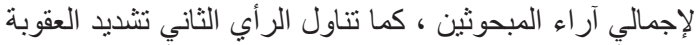

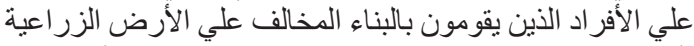

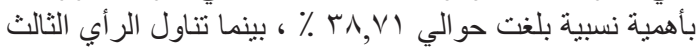

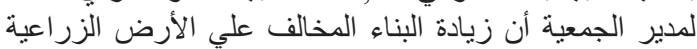

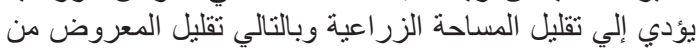

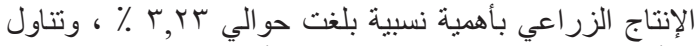

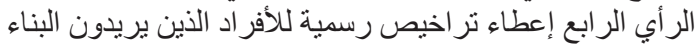

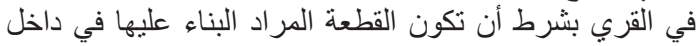

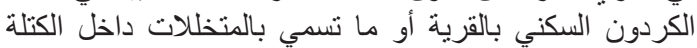

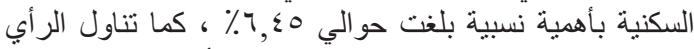

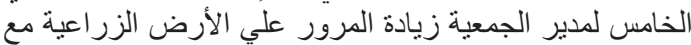

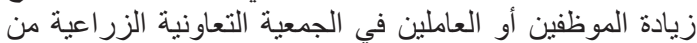

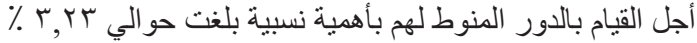
، أما الرأي السادس فقد تناول رفع سعر المنتجات الزر العية بهرف

جدول 7.

\begin{tabular}{|c|c|c|c|c|c|c|c|}
\hline الأهمية النسبية (٪) & 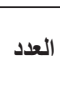 & النوع & البيان & 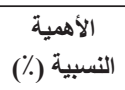 & العدد الع & النوع ل & البيان \\
\hline $\begin{array}{l}\varepsilon q, \varepsilon \\
r r, r \\
r v, r \\
1 \ldots\end{array}$ & $\begin{array}{l}\varepsilon 1 \\
19 \\
r Y\end{array}$ & مشاكل بيئة أمنية & 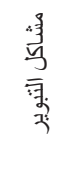 & $\begin{array}{l}r, 1 \\
1,0 \\
7 \leqslant, 7 \\
1, r\end{array}$ & $\begin{array}{l}\text { y } \\
\text { v } \\
\text { or } \\
1\end{array}$ & 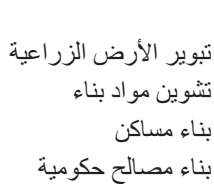 & s \\
\hline $\begin{array}{l}11 \\
1 K \\
1 \%\end{array}$ & $\begin{array}{l}\text { Vr } \\
1 \text { 1. } \\
\text { Ar }\end{array}$ & الجملة & 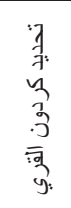 & $\begin{array}{l}7,1 \\
\varepsilon, 9 \\
1,0 \\
1 \ldots\end{array}$ & $\begin{array}{l}0 \\
\varepsilon \\
V \\
\lambda r\end{array}$ & النشاء النشاء مزمين مو (تسمين & $\begin{array}{l}\overline{7} \\
\text { y: }\end{array}$ \\
\hline $\begin{array}{l}19 \\
11 \\
11\end{array}$ & $\begin{array}{l}V T \\
q\end{array}$ & لا نعم فاعلة فاعلة & 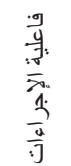 & $\begin{array}{l}11, r \\
\wedge \mu, r \\
1, .\end{array}$ & $\begin{array}{l}q \\
V T \\
A r\end{array}$ & لالجملة & 亚 \\
\hline $\begin{array}{l}r, r \\
r, \cdot \\
\wedge r, v\end{array}$ & $\begin{array}{c}0 \\
r \\
79\end{array}$ & 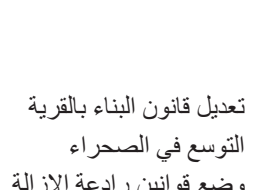 & 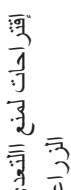 & $\begin{array}{l}r 1,9 \\
\vee \wedge, 1 \\
1 \cdots\end{array}$ & $\begin{array}{l}11 \\
1 \leq \\
1 r\end{array}$ & لا تلوت الإز الة إلة & $\begin{array}{c}\frac{y}{7} \\
3 \\
\frac{x}{2} \\
\frac{7}{7}\end{array}$ \\
\hline $\begin{array}{l}\varepsilon, \lambda \\
r, \varepsilon \\
1, \cdots\end{array}$ & $\begin{array}{l}\varepsilon \\
r \\
\text { Ar }\end{array}$ & الجملة مساكن للثباب رواده الإزاله & 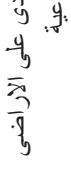 & $\begin{array}{l}7 \leqslant, r \\
1 \leqslant, r \\
v, 1 \\
1 \leqslant, r \\
1, .\end{array}$ & $\begin{array}{l}\text { or } \\
\text { Ir } \\
\text { T } \\
\text { Ir } \\
\text { Ar }\end{array}$ & 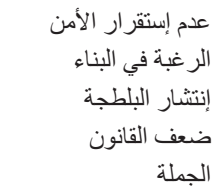 & 永: \\
\hline
\end{tabular}


توفير وقت المزارع للقيام بعطله في الحقل وزيادة الإنتاج بأهمية

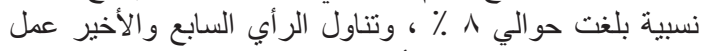

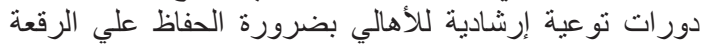

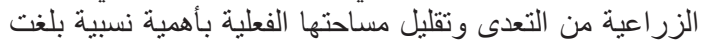

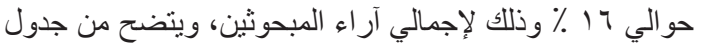

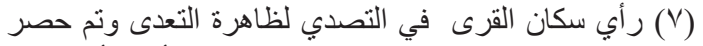

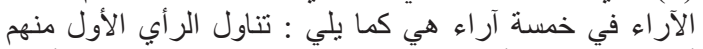

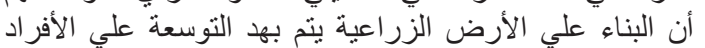

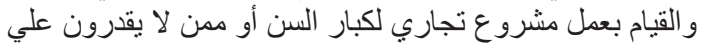

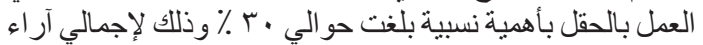

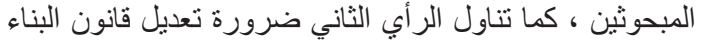

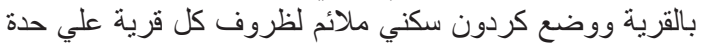

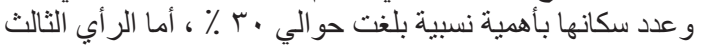

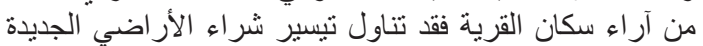

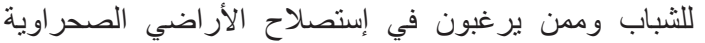

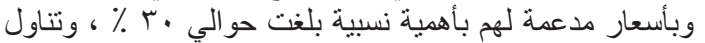

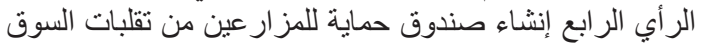

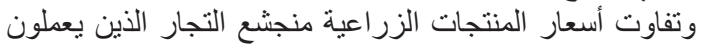

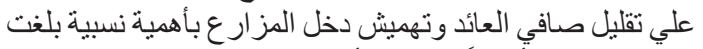

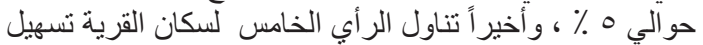

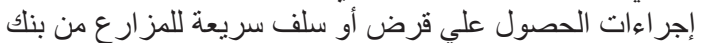

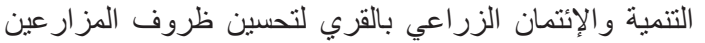

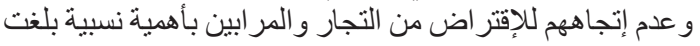
حو الي ه ٪ وذلإهـ لإجمالي آر اء المبحوثين.
وتبين من جدول (V) رأي رجال الإدارة المحلية بالقري

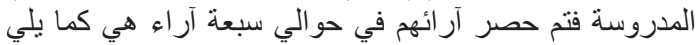

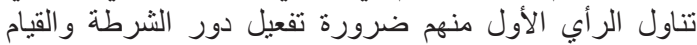

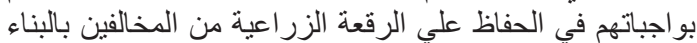

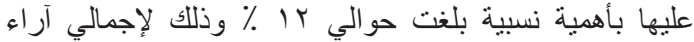

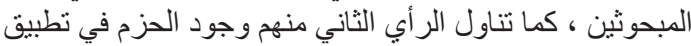

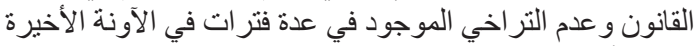

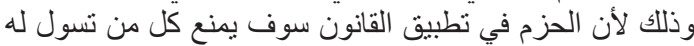

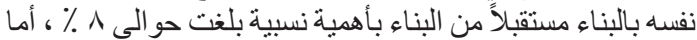

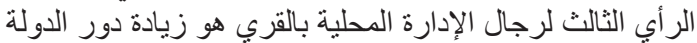

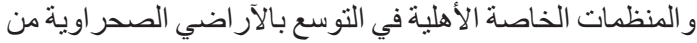

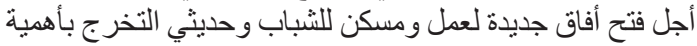

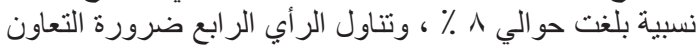

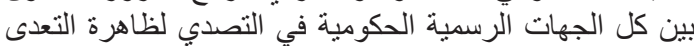

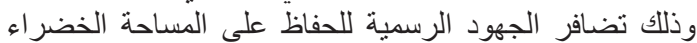

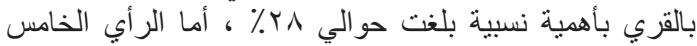

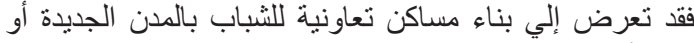

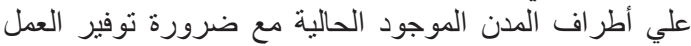

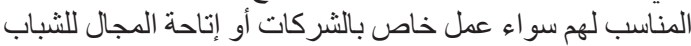

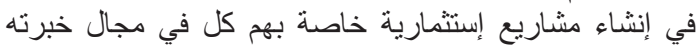

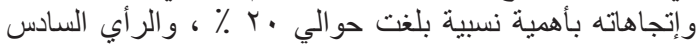

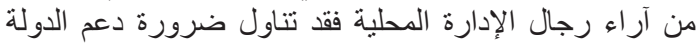

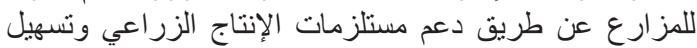
الحصول علي مستلزمات الإنتاج من بنوك الك التنمية بالزري القري بهدف

جدول V. الأهمية النسبية لآراء مدير الجمعية ومدير الحماية ورجال الإدارة وسكان القرية بعينة البحث الميدانية بمركز السنيلاوين خلال عام 9 . ب

\begin{tabular}{|c|c|c|c|c|c|c|c|}
\hline الأهمية النسبية & 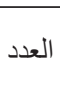 & 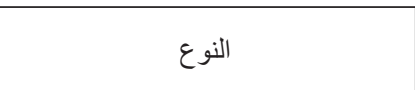 & 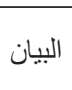 & الأهمية النسبية & العدد & 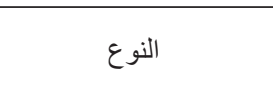 & 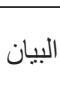 \\
\hline ir & 1. & تفعيل دور الشرطة & \multirow{8}{*}{$\begin{array}{l}\frac{7}{y} \\
\frac{1}{5} \\
\frac{5}{3} \\
\frac{7}{7}\end{array}$} & Or, ro & r & إز الة المباني كاملة & \multirow{8}{*}{ 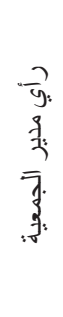 } \\
\hline$\wedge$ & $\checkmark$ & الحزم في تطبيق القانون & & $r \wedge, \vee$ & r & تشديد العقوبّة & \\
\hline$\wedge$ & $\checkmark$ & التوسع في الآر اضي الصحر اوية & & r tre & r & تقليل المساحة الزر اعية & \\
\hline rs & rt & التعاون بين الجهات الرسمية & & $7, \leqslant 0$ & 。 & إعطاء تر اخيص " " & \\
\hline r. & 17 & عمل مساكن تعاونية للشباب & & r & r & زيادة المرور علي الأرض & \\
\hline$\wedge$ & $\checkmark$ & دمم الدولة للمزارع & & ir,q. & 11 & رفع سعر المنتجات الزر اعية & \\
\hline 17 & ir & عمل دور ات توعية للآهالي & & r & r & زيادة دور العمد و المشايخ & \\
\hline $1 \ldots$ & Ar & الجملة & & $1 \ldots$ & $\lambda r$ & الجملة الجما & \\
\hline r. & ro & التوسعة و عمل مشروع تجاري & \multirow{6}{*}{ 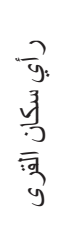 } & \multirow{6}{*}{$\begin{array}{l}10, r \Lambda \\
r \Lambda, \leqslant V \\
10, r \Lambda \\
r \cdot, r V \\
1 \ldots\end{array}$} & \multirow{6}{*}{$\begin{array}{l}\text { it } \\
\text { hr } \\
\text { it } \\
\text { ro }\end{array}$} & \multirow{6}{*}{ تفعيل الكود غرامات مالية } & \multirow{6}{*}{$\begin{array}{l}\frac{7}{y}: \\
\frac{7}{2} \\
\overline{3} \\
\frac{7}{3}\end{array}$} \\
\hline r. & ro & تعديل قانون البناء بالقرية & & & & & \\
\hline r. & ro & تيسير شر اء الآر اضي الجديدة & & & & & \\
\hline$\circ$ & $\varepsilon$ & إنشاء صنوق حماية للمز ارعين . ئ. & & & & & \\
\hline 0 & $\varepsilon$ & تسهيل الحصول علي قرض من بنك التنمية & & & & & \\
\hline $1 \cdots$ & AT & الجملة & & & & & \\
\hline
\end{tabular}

المصدر : جمعت وحسبت من إستمارةالإستبيانبعينةالبحث الميدانبة بمحافظة الدقهلية خلال عام 9 ـــ. 


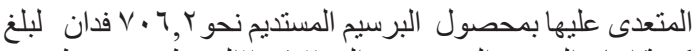

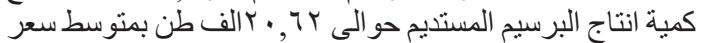

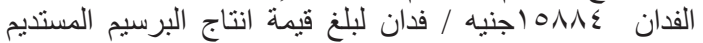

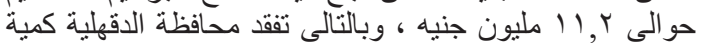

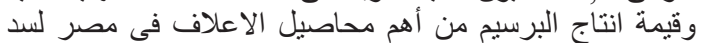

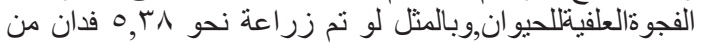

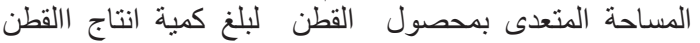

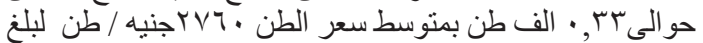

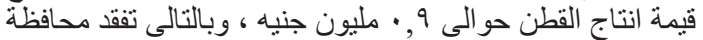

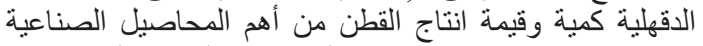

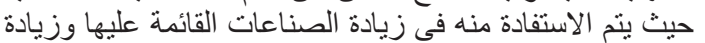

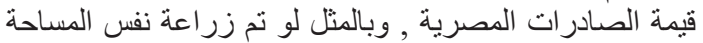

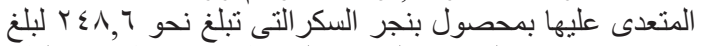

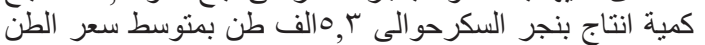

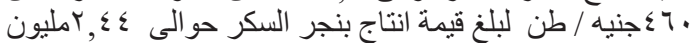

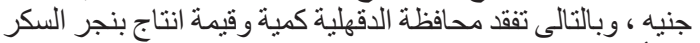

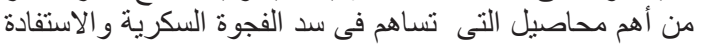

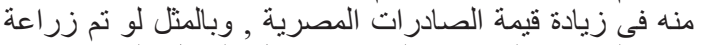

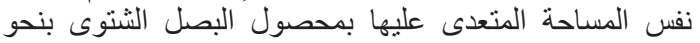

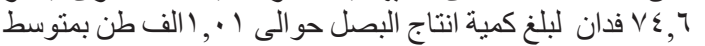

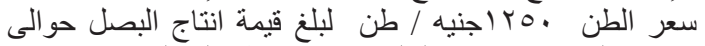

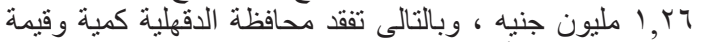

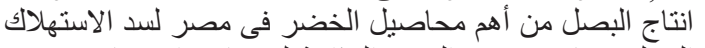

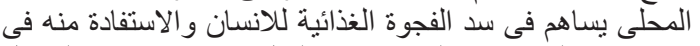

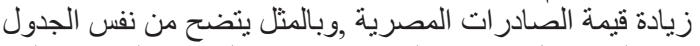

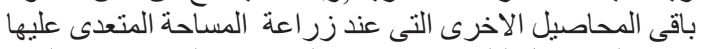

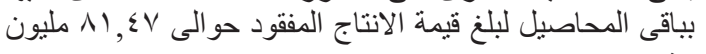

تاسعا : الآثار الاقتصادية الناتجة عن التعدى بالبناء على الارض الإض

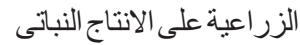
1 ـالاثار الاقتصادية للتعدى على مساحة وكمية وقيمة الانتاج المفقود لبعض المحاصيل بمحافظة الاقهائية:

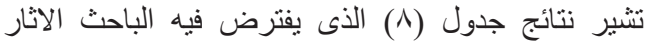

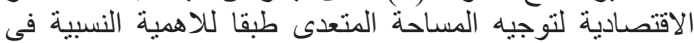

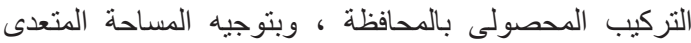

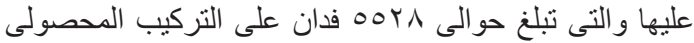

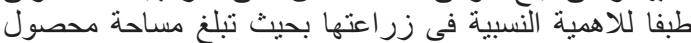

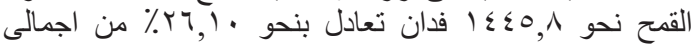

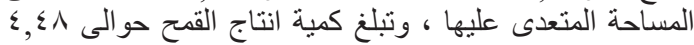

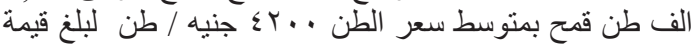

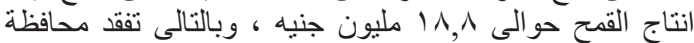

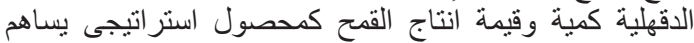

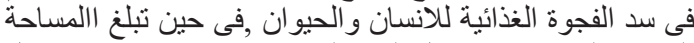

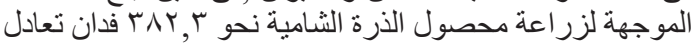

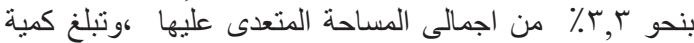

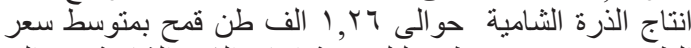

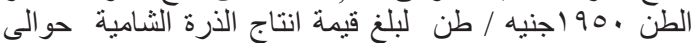

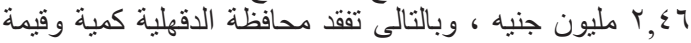

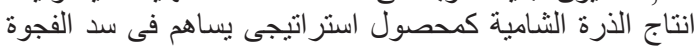

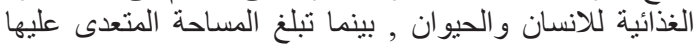

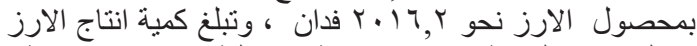

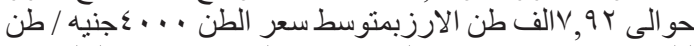

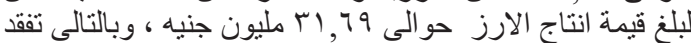

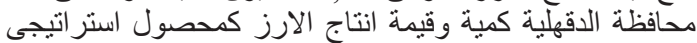

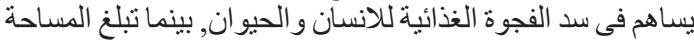

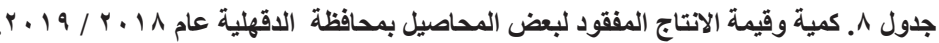

\begin{tabular}{|c|c|c|c|c|c|c|c|}
\hline بالمليون الانتاج & الطن بالجنيه & بالالف طن & بالطناجية & المساحة المفقودة & $\%$ & المساحة المزروعة & المحصول \\
\hline$I A, A r$ & $\varepsilon r .$. & $\varepsilon, \varepsilon \wedge$ & r, & $1 \leq \leqslant 0, \wedge$ & $r 7,10$ & ২৭११. & القمح \\
\hline$\cdot, V T$ & $90 \ldots$ & $\cdot, \cdot \wedge$ & 1,ro & $07, r$ & $1, \cdot r$ & 11779 & الفول \\
\hline$r, \Sigma \varepsilon$ & $\leq 7$. & $0, r$ & $r, r$ & $r \leq \wedge, T$ & $\varepsilon, 0$ & 01074 & بنجر السكر \\
\hline $11, r$ & $101 \mathrm{NE}$ & $r \cdot, \pi r$ & $r q, r$ & $V \cdot 7, r$ & $M, V Y$ & $1 \leqslant 7 \leqslant \vee 9$ & البرسيم المستديم \\
\hline$\cdot, \cdots \varepsilon$ & $\varepsilon \ldots$ & $\cdot, \cdots 1$ & $1, T V$ & $\cdot, 7$ & $\cdot, \cdot 1$ & Irr & شعير \\
\hline$\cdot, 1$ & 1704 & $\cdot, \cdot 4$ & $\varepsilon, r r$ & $1 \leqslant, \varepsilon$ & $\cdot, r 4$ & rqv & كتان \\
\hline $1, r 7$ & ro. & $1, \cdot 1$ & $1 \pi, 0$ & $v \varepsilon, 7$ & 1, ro & loEAr & بصل \\
\hline$\cdot, I r$ & $1 \leqslant 9$. & $\cdot, \cdot \wedge$ & $1 \leqslant, \wedge$ & 0,7 & $\cdot, 1$ & 1178 & طماطم شتوى \\
\hline 1,or & $1 \leqslant 07$ & $1, \cdot 0$ & $1 \cdot, 7$ & $9 \wedge, 9$ & 1,199 & r.or. & بطاطس شتوى \\
\hline$v, q \leq$ & Vq $\leqslant r$ & $1, \cdot 0$ & $I T, V$ & $\lambda r, \wedge$ & 1,0 & 16174 & برسيم تحريش \\
\hline$r, 79$ & $\varepsilon \ldots$ & $v, q r$ & r,qr & $r \cdot 17, r$ & $r 4, \leqslant V$ & EIAYro & ارز \\
\hline$r, \leqslant 7$ & 190. & $1, r 4$ & $r, r$ & $r \lambda r, r$ & 7,94 & VवYवV & ذرة شامية \\
\hline$\cdot, 9$ & rVY. & r & 1,1 & rqv, r & $0, r \wedge$ & זדצוד & قطن \\
\hline $1, \cdot r$ & $1 v \cdot 1$ & $\cdot, 7$ & 17,7 & $r o, 9$ & $\cdot, 70$ & $V \leqslant 01$ & طماطم صيفى \\
\hline $1, r 4$ & 170. & $\cdot, 14$ & $M, r$ & $T$ & $1,1 r$ & Irवqr & بطاطس صيفى \\
\hline$\wedge, \leqslant V$ & & $\leqslant \leqslant, 7$ & & $00 \mathrm{rA}$ & $1 \ldots$ & $11 \leq 77 V 7$ & الاجمالى \\
\hline
\end{tabular}


Alshaal, T., and El-Ramady, H (2017) Sustainable Agriculture: Towards Holistic Overview Journal of Sustainable Agriculture Science, Vol. 43, Issue2 .pp: 65-67.

Moussa, M. Z.) 1989 (Econometric Estimation of Frontier Production Function and Measurement of Technical Efficiency of Corn Crop Farms in KafrEl_Sheikh Governorate», Journal of Agric Sciences, Vol. 15, No. 4, Tanta Univ.,
التوصيات

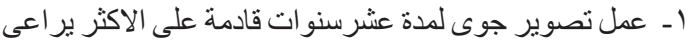

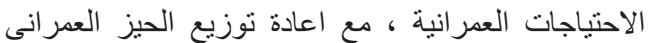

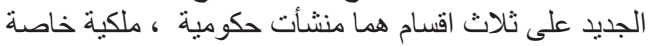
مساكن اجتماعية للشباب.

r - اعادة النظر فى مشروع القوانين المتعلقة بالتعديات حيث مقيث

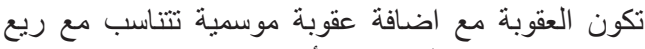
الارض من محصول صيفى وأنة وأخر شتوى.

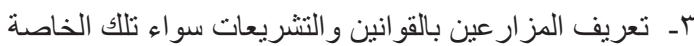
بالبناء أو التبوير لكى يكون ذللك إنذار لغير هم من المو اطنين.

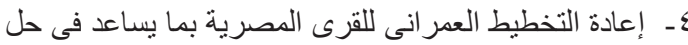

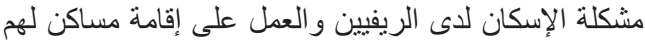
خارج المناطق الزر اعية وبشروط ميسرة.

0ـ ضرورة در اسة إحتياجات المحاصبل من المقرر ات السمادية

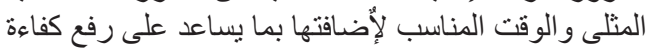

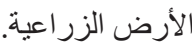

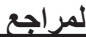

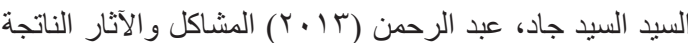

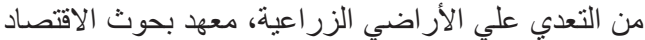

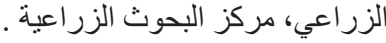

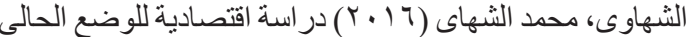

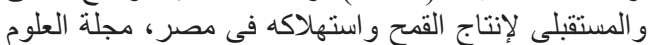

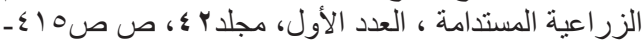

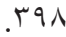

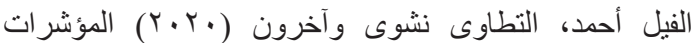

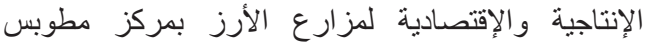

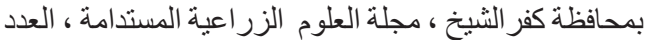

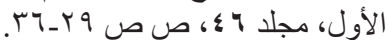

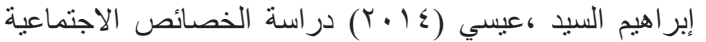

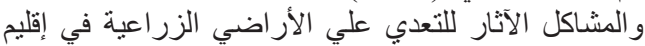

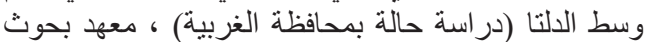
الاقتصاد الزراعي، مركز البحوث الزراعية.

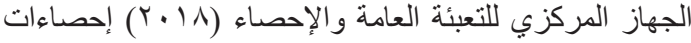
استصلاح و استزر اع الأر اضينة في مصر.

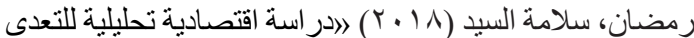

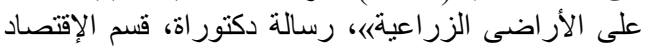

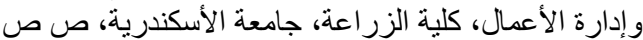
A.-9r

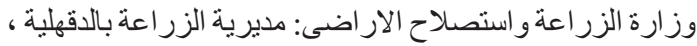

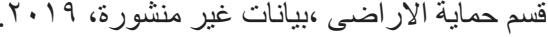




\section{An Analytical Study of The Economic Effects of The Encroachment on Agricultural Lands in Dakahlia Governorate (Acase Study of Sinbilliwain)}

$\mathbf{T}$

HE PHENOMENON of encroachment on agricultural lands is considered a major economic problem facing the Egyptian national economy, given that the agricultural land resource is not sufficient to meet the human and animal needs of the necessary agricultural commodities due to the low agricultural production that negatively affects the Egyptian national economy, as the encroached area in Dakahlia Governorate reached about 5528 acres, representing about 7,3\% of the total area of encroachment at the level of the Republic in 2019, The study aimed to address the phenomenon of encroachment on agricultural lands in all its various forms that threaten food security in Egypt in general and the Dakahlia Governorate in particular so that the phenomenon of encroachment at the governorate level and the national level can be explained through a set of goals, came in the eighth position in Dakahlia Governorate where cases of encroachment were estimated About 101,1 thousand cases, representing about $6,2 \%$ of the total number of cases of encroachment on agricultural lands on an area of 5086 acres, representing about 7,1\% of the total area of land encroachment, the Dakahlia Governorate came in the field of study.

KeyWords: Encroachment, Building Violation, Buildozing, Land Resources, Food Security, Public Property, Private Property. 